\title{
Diagnosis and management of transthyretin familial amyloid polyneuropathy in Japan: red-flag symptom clusters and treatment algorithm
}

\author{
Yoshiki Sekijima ${ }^{1}$, Mitsuharu Ueda², Haruki Koike ${ }^{3}$, Sonoko Misawa ${ }^{4}$, Tomonori Ishii ${ }^{5}$ and Yukio Ando ${ }^{2 *}$
}

\begin{abstract}
Hereditary ATTR (ATTRm) amyloidosis (also called transthyretin-type familial amyloid polyneuropathy [ATTR-FAP]) is an autosomal-dominant, adult-onset, rare systemic disorder predominantly characterized by irreversible, progressive, and persistent peripheral nerve damage. TTR gene mutations (e.g. replacement of valine with methionine at position 30 [Val30Met (p.Val50Met)]) lead to destabilization and dissociation of TTR tetramers into variant TTR monomers, which form amyloid fibrils that deposit in peripheral nerves and various organs, giving rise to peripheral and autonomic neuropathy and several non-disease specific symptoms.

Phenotypic and genetic variability and non-disease-specific symptoms often delay diagnosis and lead to misdiagnosis. Red-flag symptom clusters simplify diagnosis globally. However, in Japan, types of TTR variants, age of onset, penetrance, and clinical symptoms of Val30Met are more varied than in other countries. Hence, development of a Japan-specific red-flag symptom cluster is warranted. Presence of progressive peripheral sensory-motor polyneuropathy and $\geq 1$ red-flag sign/symptom (e.g. family history, autonomic dysfunction, cardiac involvement, carpal tunnel syndrome, gastrointestinal disturbances, unexplained weight loss, and immunotherapy resistance) suggests ATTR-FAP. Outside of Japan, pharmacotherapeutic options are first-line therapy. However, because of positive outcomes (better life expectancy and higher survival rates) with living donor transplant in Japan, liver transplantation remains first-line treatment, necessitating a Japan-specific treatment algorithm.

Herein, we present a consolidated review of the ATTR-FAP Val30Met landscape in Japan and summarize findings from a medical advisory board meeting held in Tokyo on 18th August 2016, at which a Japan-specific ATTR-FAP red-flag symptom cluster and treatment algorithm was developed. Beside liver transplantation, a TTR-stabilizing agent (e.g. tafamidis) is a treatment option. Early diagnosis and timely treatment using the Japan-specific red-flag symptom cluster and treatment algorithm might help guide clinicians regarding apt and judicious use of available treatment modalities.
\end{abstract}

Keywords: Disease-modifying agent, Tafamidis, Liver transplantation, Hereditary ATTR amyloidosis, Familial amyloid polyneuropathy, Amyloidosis neuropathy, Carpal tunnel syndrome, Cardiomyopathy, Red-flag symptom clusters

\footnotetext{
* Correspondence: andoy709@kumamoto-u.ac.jp

${ }^{2}$ Department of Neurology, Graduate School of Medical Sciences, Kumamoto

University, 1-1-1 Honjo, Chuo-ku, Kumamoto-shi, Kumamoto 860-8556, Japan

Full list of author information is available at the end of the article
}

(c) The Author(s). 2018 Open Access This article is distributed under the terms of the Creative Commons Attribution 4.0 International License (http://creativecommons.org/licenses/by/4.0/), which permits unrestricted use, distribution, and reproduction in any medium, provided you give appropriate credit to the original author(s) and the source, provide a link to the Creative Commons license, and indicate if changes were made. The Creative Commons Public Domain Dedication waiver (http://creativecommons.org/publicdomain/zero/1.0/) applies to the data made available in this article, unless otherwise stated. 


\section{Background}

Transthyretin-type familial amyloid polyneuropathy (ATTR-FAP), or hereditary transthyretin amyloidosis (ATTRm amyloidosis), is an autosomal-dominant, adultonset, rare systemic disorder predominantly characterized by irreversible, progressive, and persistent peripheral nerve damage $[1,2]$. ATTR-FAP can present as a progressive, axonal, sensory autonomic and motor neuropathy, restrictive cardiomyopathy (transthyretin cardiomyopathy), or as a cerebral amyloid angiopathy; however, most cases are classified as neuropathic [1]. In analysis of data from the Ministry of Health, Labour and Welfare, Japan (MHLW), during 2003-2005, 110.8-135.4 cases of familial amyloidosis were found, equating to an estimated prevalence of $0.87-1.1$ per $1,000,000$ persons; the highest prevalence was in the Nagano prefecture, followed by Kumamoto, and Ishikawa (11.0-15.5, 10.1-10.3, and 3.54.2 per 1,000,000 persons, respectively) [3].

TTR - a homotetramer plasma transport protein that carries thyroxine and retinol-binding protein-is produced primarily in the liver but also in the choroid plexus and retinal pigment epithelium, and is secreted into the blood, cerebrospinal fluid, and eye, respectively [1, 4-9].

There are over 130 different TTR gene mutations identified worldwide, of which $>40$ mutations are linked with ATTR-FAP in Japan (Table 1). However, replacement of valine with methionine at position 30 (ATTRFAP Val30Met [p.Val50Met]) is the most commonly observed mutation, the only one found in large foci of patients, and is associated primarily with neuropathy $[1,10]$. TTR gene mutations destabilize TTR, leading to dissociation of tetramers and partial unfolding of resultant monomers. Variant TTR monomers aggregate to form amyloid fibrils [1, 11-13]. Because of diffuse amyloid fibril deposition (e.g. in the extracellular space in peripheral nerves, heart, gastrointestinal tract, kidneys, eyes,

Table 1 ATTR-FAP linked genetic mutations in Japan

\begin{tabular}{ll}
\hline Main symptoms & Genetic mutations \\
\hline $\begin{array}{l}\text { Peripheral } \\
\text { neuropathy }\end{array}$ & Ala25Ser, Val30Leu, Phe33Val, Asp38Ala, Glu42Gly, \\
& Phe44Ser, Gly47Arg, Gly47Val, Thr49lle, Thr49Ala, \\
& Ser50Arg, Glu54Lys, Leu55Pro, Glu61Lys, Val71Ala, \\
& Ser77Tyr, Ala97Gly, Ala109Ser, Val28Ser, Val28Met, \\
& Ala36Pro, Ile84Asn, His88Arg, Ala120Ser \\
CTS + peripheral & Leu58Arg, Tyr69lle, Ile107Val, Tyr114His, Ala120Ser, \\
neuropathy & Ala120Thr \\
Cardiac & Asp18Glu, Ala36Asp, Ala45Asp, Ser50lle, Thr59Arg, \\
& Thr60Ala, Glu89Lys, Gln92Lys, Val94Gly, Asp38Ala, \\
& Ser50Arg, Val122lle, Glu89GIn, Pro24Ser, Val30Leu \\
Leptomeningeal & Ala25Thr, Gly53Glu, Tyr114Cys, Asp18Gly, Tyr69His \\
Non-pathologic & Arg104His \\
Compound & Val30Met/Arg104His \\
heterozygosity &
\end{tabular}

ATTR-FAP Transthyretin familial amyloid polyneuropathy, CTS Carpal tunnel syndrome meninges, vessels, and connective tissue of the transverse carpal ligament) [14], ATTR-FAP is associated with various symptoms, many of which are non-specific $[1,11,15]$. Disease onset, which occurs between the 10s and 90s, is generally classified as early-onset $(<50$ years old) and lateonset ( $\geq 50$ years old) $[16,17]$. Within approximately 10 years of disease onset, progressive organ dysfunction and death (due to cardiac dysfunction, infection, or cachexia) occur [1, 18-21]. Several studies have indicated that onset of ATTR-FAP symptoms in Japan is bimodal, with one peak occurring in the 30 s to 40 s (early-onset) and another distinct peak in the 60 s (late-onset) [1, 3, 16, 22-24]. In contrast, other countries have a single peak of symptom onset (e.g. between 25 and 35 years with a mean of 33.5 years in Portugal and in the 50 s or 60 s in Sweden) [25-27] (Fig. 1; Pfizer Inc., data on file).

In addition to heterogeneity of amyloidogenic TTR mutations and variability in the age of onset, phenotypic heterogeneity at various levels makes ATTR-FAP diagnosis challenging. Carriers of the same TTR point mutation may exhibit very different clinical manifestations, even among family members [1]. Also, absence of family history in non-endemic areas, and sporadic cases present additional diagnostic challenges [28-31]. As ATTR-FAP is a progressive disease and can cause largely irreversible tissue damage, timely recognition and diagnosis are critical for appropriate treatment and optimal outcomes [32-34]. Unfortunately, diagnosis of ATTR-FAP is often delayed because of phenotypic and genetic variability, varied clinical presentation, and the non-specific nature of most symptoms [1, 19, 30, 31, 35]. Misdiagnosis also may occur for similar reasons (see Common diagnostic pitfalls).

In the past decade, the situation surrounding ATTRFAP and its treatment has changed dramatically in Japan: owing to heightened awareness of the disease, the number of ATTR-FAP patients in this country has reportedly increased from 110.8-135.4 [3] to approximately 300 (Sekijima et al., unpublished observations). In terms of treatment, liver transplantation (LT) has been the only standard of care since the 1990s [1, 36-41]; in the early 2010s, however, treatment options were widened by the advent of minimally invasive, disease-modifying pharmacotherapy such as TTR tetramer stabilizer [1, 35, 42]. Nevertheless, a number of patients with ATTR-FAP still remain undiagnosed and thus untreated because of diverse clinical presentations and various non-specific symptoms of the disease; especially in Japan, presence of diverse types of patients (e.g. early-onset Val30Met in endemic areas, late-onset Val30Met in non-endemic areas, non-Val30Met variants whose cardinal symptoms are cardiomyopathy, carpal tunnel syndrome, or cerebral amyloid angiopathy) often makes accurate diagnosis difficult $[15,16,24,43-45]$. 


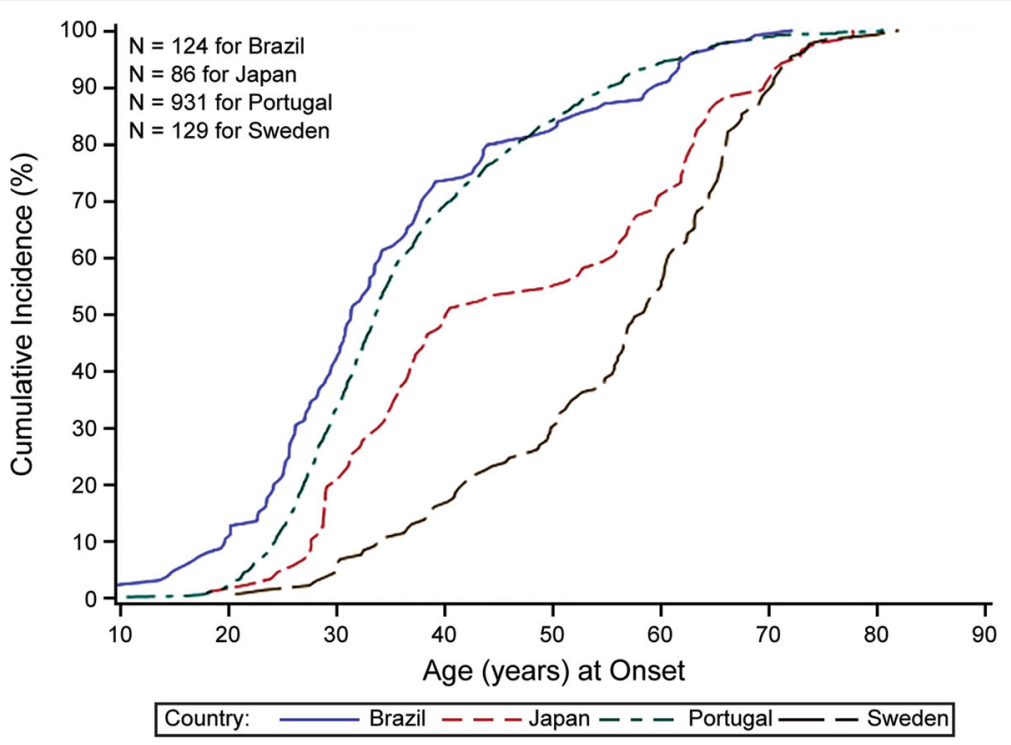

Fig. 1 Cumulative onset of symptomatic disease: Val30Met in four countries

In view of the enormous possibility of misdiagnosis or delayed diagnosis, Conceição and colleagues reported red-flag symptom clusters suggestive of ATTR-FAP and treatment algorithms [46]. However, these clusters and algorithms are not necessarily applicable to Japan because situations specific to this country (e.g. presence of diverse types of patients) are not fully reflected. Herein, we provide a consolidated review of the worldwide landscape of ATTR-FAP and our treatment experience in Japanese ATTR-FAP patients to propose revised red-flag symptom clusters and treatment algorithm.

\section{Methods}

The authors (YS, MU, HK, SM, and YA) held a medical advisory board meeting in Tokyo, Japan on 18th August 2016 with the aim to promote early diagnosis and to stipulate consensus on diagnosis and management of ATTR-FAP Val30Met in Japan. The red-flag symptom clusters and treatment algorithm presented in this article are developed as per findings from this medical advisory board meeting.

\section{Clinical features}

ATTR-FAP Val30Met can be endemic (i.e. localized to a small area, with a traceable family history and earlyonset of the disease) or non-endemic (i.e. scattered, frequently without family history, and late-onset of the disease) [3, 16, 29-31, 34, 47]. The clinical picture of ATTR-FAP differs between patients from endemic and non-endemic areas $[1,15,16,48]$. Generally, patients from endemic areas have early-onset disease, while those from non-endemic areas have late-onset disease $[15,16,20,44,49]$. In Japan, however, despite an identical TTR genotype and generally homogenous ethnic background, two major ATTR-FAP Val30Met phenotypes have been identified: early-onset and endemic (Nagano and Kumamoto), and late-onset and non-endemic [16, 20,31]. Common clinical features of the early-onset and endemic phenotype in Japan resemble those of Portuguese FAP patients [10, 27, 50, 51], while clinical features of the late-onset phenotype in non-endemic areas are distinct from those phenotypes $[16,20,31]$. Differences in clinical features between early-onset and late-onset disease are presented in Table 2. Early-onset ATTR-FAP generally starts between the late 20 s to the early 40 s and is characterized by predominant loss of superficial sensation including nociception and thermal sensation (i.e. sensory dissociation), presence of family history, high penetrance rate, severe autonomic dysfunction, and atrioventricular conduction block requiring pacemaker implantation $[15,16,49,52-$ 54]. On the other hand, late-onset disease starts after 50 years of age and is characterized by sensorimotor symptoms beginning in the distal lower extremities, initial involvement of both superficial and deep sensation, loss of all sensory modalities rather than sensory dissociation, low penetrance rate, relatively mild autonomic dysfunction, frequent presence of cardiomegaly, and extreme male preponderance [15, 16, 24, 31, 55]. Genetic anticipation is frequently considered a differentiating feature due to its presence in early-onset disease and its absence in lateonset disease $[43,56]$. However, the occurrence of anticipation may be overestimated since not all asymptomatic individuals undergo molecular genetic testing, and hence some asymptomatic individuals with the Val30Met variant may not be identified [57]. 
Table 2 Comparison of clinical features between early-onset and late-onset ATTR-FAP

\begin{tabular}{|c|c|c|}
\hline Clinical feature & Early-onset & Late-onset \\
\hline Age of onset of symptoms & - Late 20s to early 40s [79] & $\cdot \geq 50$ years $[16,20,24]$ \\
\hline Penetrance & • High penetrance rate [16] & • Low penetrance rate [24] \\
\hline Pattern of neuropathic symptoms & $\begin{array}{l}\text { - Loss of superficial sensation, including } \\
\text { nociception and thermal sensation } \\
\text { (i.e. sensory dissociation) [16] }\end{array}$ & $\begin{array}{l}\text { - Loss of all sensory modalities rather than } \\
\text { sensory dissociation. Impaired superficial } \\
\text { and deep sensation, neuropathic pain, } \\
\text { early distal motor involvement }[31,92]\end{array}$ \\
\hline Family history of ATTR-FAP & - Common [24] & • Frequently absent [24] \\
\hline Autonomic dysfunction & $\begin{array}{l}\text { - Severe, life-threatening autonomic } \\
\text { dysfunction [16] }\end{array}$ & - Relatively mild autonomic symptoms [16] \\
\hline Other features & $\begin{array}{l}\text { - Atrioventricular conduction block requiring } \\
\text { pacemaker implantation } \\
\text { - Weight loss } \\
\text { - Muscle wasting [16] }\end{array}$ & $\begin{array}{l}\text { - Extreme male preponderance } \\
\text { - Frequent presence of cardiomegaly }[92,157]\end{array}$ \\
\hline
\end{tabular}

ATTR-FAP Transthyretin familial amyloid polyneuropathy

The clinical and paraclinical features of ATTR-FAP are presented in Fig. 2. In general, fiber length-dependent peripheral sensory-motor neuropathy is a hallmark feature of ATTR-FAP [1, 15]. A number of previously reported studies have discussed initial symptoms in ATTR-FAP patients in Japan [15, 16, 20, 31, 45, 46, 50]. The initial symptoms in Japanese ATTR-FAP patients are presented in Table 3. Symptoms of ATTR-FAP can be broadly divided into neuropathic symptoms and other systemic symptoms as described below.

\section{Neuropathic symptoms}

In classical early-onset disease, damage is first observed in distal small myelinated and unmyelinated nerve fibers associated with pain and temperature and manifests as paresthesia, dysesthesia, allodynia,

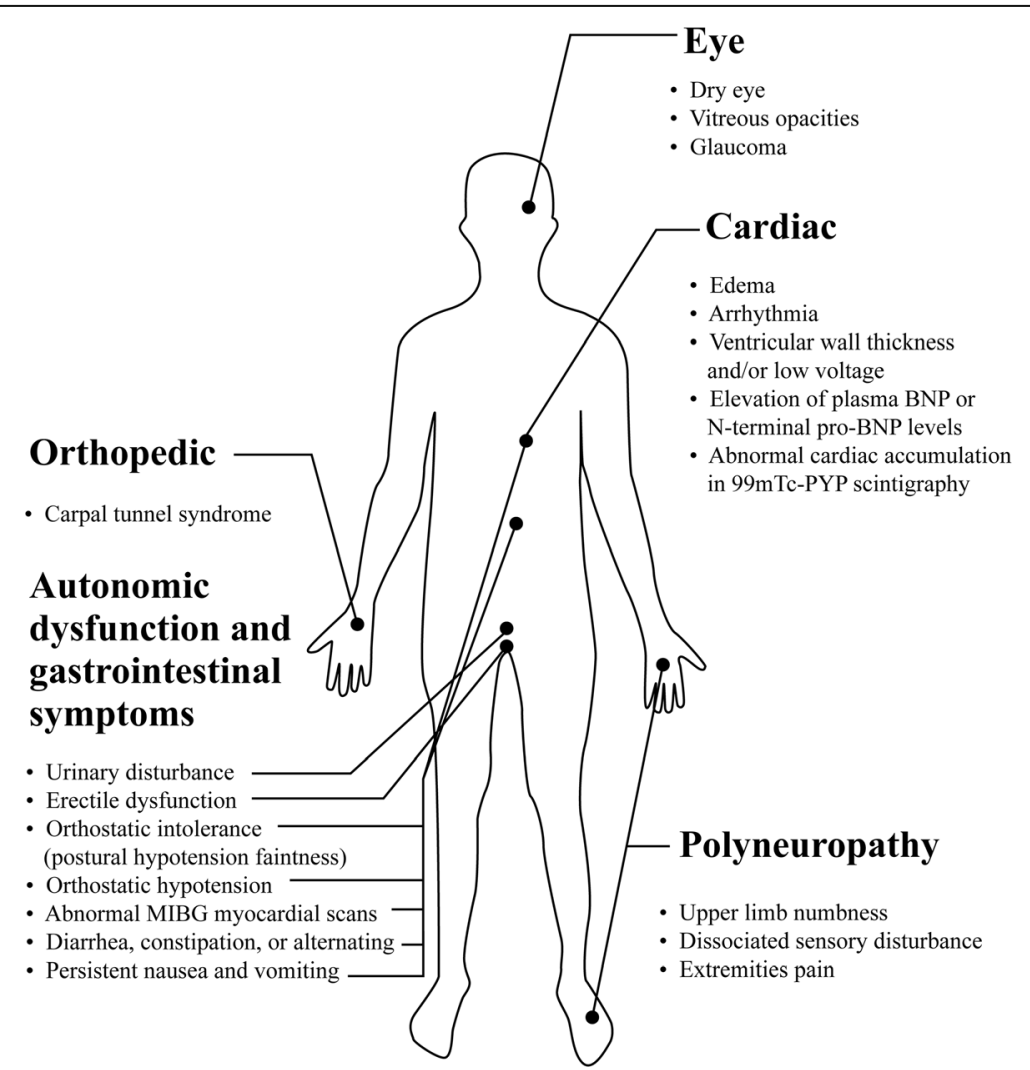

Fig. 2 Clinical and paraclinical features of ATTR-FAP. BNP brain natriuretic peptide, TC-PYP Tc-pyrophosphate scintigraphy, MIBG metaiodobenzylguanidine 
Table 3 Initial symptoms of ATTR-FAP Val30Met patients in Japan

\begin{tabular}{|c|c|c|c|c|c|}
\hline & \multirow[t]{2}{*}{ Ando $Y$ et al., 2005 [52] } & \multirow{2}{*}{$\frac{\text { lkeda S et al., } 1987 \text { [53] }}{\text { Early onset }^{a}}$} & \multicolumn{2}{|c|}{ Koike $\mathrm{H}$ et al., 2002 [16] } & \multirow{2}{*}{$\frac{\text { Koike } \mathrm{H} \text { et al., } 2012 \text { [20] }}{\text { Late onset }^{\mathrm{b}}}$} \\
\hline & & & Early onset $^{a}$ & Late onset ${ }^{\mathrm{b}}$ & \\
\hline Patients, $n$ & 117 & 45 & 82 & 59 & 50 \\
\hline Mean \pm SD age of onset, years & 35.3 & $33.4^{c}, 34.2^{d}$ & $31.9 \pm 7.6$ & $62.5 \pm 6.2$ & $64.5 \pm 6.5$ \\
\hline \multicolumn{6}{|l|}{ Sensory-motor symptoms, n (\%) } \\
\hline Sensory disturbances in lower limbs & $52(44.4)$ & $22(48.9)$ & & & \\
\hline Neuropathic symptoms & & & $47(57.3)$ & $48(81.4)$ & $40(80.0)$ \\
\hline \multicolumn{6}{|l|}{ Carpal tunnel syndrome } \\
\hline Muscle weakness in lower limbs & $3(2.6)$ & $3(6.7)$ & & & \\
\hline Autonomic and Gl symptoms, n (\%) & $48(41.0)$ & $19(42.2)$ & $39(48.0)$ & $6(10.2)$ & \\
\hline Autonomic symptoms & $10(8.5)$ & & & & $5(10.0)$ \\
\hline Erectile dysfunction/impotence & $5(4.3)$ & $4(8.9)$ & & & \\
\hline Orthostatic hypotension/faintness/syncope & $5(4.3)$ & $3(6.7)$ & & & \\
\hline Gl symptoms & $38(32.5)$ & & & & \\
\hline Anorexia & & $2(4.4)$ & & & \\
\hline Constipation & & $8(17.8)$ & & & \\
\hline Diarrhea & & $2(4.4)$ & & & \\
\hline Weight loss, $n(\%)$ & & & $4(4.9)$ & 0 & \\
\hline Cardiac symptoms, n (\%) & $5(4.3)$ & & 0 & $3(5.1)$ & $2(4.0)$ \\
\hline Renal dysfunction, $n$ (\%) & $5(4.3)$ & & & & \\
\hline Ocular symptoms, n (\%) & $4(3.4)$ & & 0 & $1(1.7)$ & $3(6.0)$ \\
\hline Bullous formations, $n$ (\%) & & $1(2.2)$ & & & \\
\hline
\end{tabular}

ATTR-FAP Transthyretin familial amyloid polyneuropathy, Gl Gastrointestinal, SD Standard deviation, Val30Met Replacement of valine with methionine at position 30 in the TTR gene

${ }^{a}$ Age $<50$ years at symptomatic disease onset

${ }^{\mathrm{b}} \mathrm{Age} \geq 50$ years at symptomatic disease onset

cMen, $n=23(51.1 \%)$

${ }^{\mathrm{d}}$ Women, $n=22$ (48.9\%)

hyperalgesia, or spontaneous pain in the feet $[15,16]$ and impaired thermal sensitivity with decreased pinprick sensation on clinical examination $[1,15,16]$. Larger myelinated sensory and motor nerve fibers are affected over the following years, impairing light touch, vibration, and position sensation. Further length-dependent progression leads to distal lower limb motor deficit, resulting in walking difficulty and weakness [15]. In late-onset disease, unmyelinated nerve fibers are preserved, and axonal sprouting is observed [15]. Autonomic dysfunction presents as sexual impotence; disturbances of gastrointestinal motility, most commonly diarrhea alternating with constipation but also constipation, diarrhea, nausea, and vomiting; orthostatic hypotension; and neurogenic bladder $[16,20,58]$. These autonomic symptoms are relatively mild in late-onset disease particularly in the early phase of neuropathy $[16,20]$. Symptoms of the lower limbs usually precede those of the upper limbs by several years in earlyonset disease, while the involvement of the upper and lower limbs may appear simultaneously in late-onset disease [20]. Occasionally carpal tunnel syndrome (CTS) may appear in the patients with non-Val30Met and lead to diagnosis in the progression of systemic neuropathy after carpal tunnel release surgery [1,59-62].

\section{Other systemic symptoms}

In addition to nervous tissue, amyloid fibrils may deposit in various organs and tissues resulting in progressive dysfunction [1, 14, 15, 63-66]. Amyloid deposition in the media and adventitia of medium-sized and small arteries, arterioles, and, occasionally, veins of the subarachnoid space, leptomeninges, and cerebral cortex leads to transient focal neurological episodes, cerebral infarction and hemorrhage, hydrocephalus, ataxia, spastic paralysis, convulsion, and dementia $[1,61,62,64,67]$. Infiltration of amyloid fibrils in cardiovascular structures such as the conduction system may lead to bundle branch block and, occasionally, atrioventricular and sinoatrial block [15]. Myocardial infiltration may lead to cardiomyopathy, with a hypertrophic phenotype and restrictive pathophysiology [1, 68]. Deposition of amyloid fibrils in the eye may cause ocular manifestations such as abnormal conjunctival vessels, keratoconjunctivitis sicca, pupillary 
abnormality, vitreous opacity, and glaucoma [69]. Amyloid fibril deposition in the kidney might lead to microalbuminuria, which often precedes subjective symptoms of ATTR-FAP. Renal involvement, including nephritic syndrome and progressive renal failure, occurs in about one-third of patients in Portugal [70]; however, severe renal dysfunction rarely occurs in Japanese ATTR-FAP patients. Further, as the kidney is the major site of erythropoietin production, anemia might develop because of significantly lower serum erythropoietin levels [71].

\section{Non-specific symptoms}

Weight loss, muscle wasting and atrophy, hoarseness, coldness, decreased skin temperature, dyscoria, dysesthesia, dissociated anesthesia, arrhythmia, edema, burning, and Charcot's joint also may be present in patients with ATTRFAP $[1,16]$.

\section{Japan-specific red flag symptom clusters}

Heritability and multisystem involvement are characteristic features of ATTR-FAP [46]. Red-flag symptom clusters suggestive of ATTR-FAP reported by Conceição and colleagues included: family history; early autonomic dysfunction; gastrointestinal complaints; unexplained weight loss; cardiac hypertrophy, arrhythmias, ventricular blocks, or cardiomyopathy; bilateral CTS; renal abnormalities; and vitreous opacities [46]. In the light of published literature and the medical advisory board's expert opinion, red-flag symptom clusters suggesting ATTR-FAP in Japan are reviewed and presented below (Fig. 3). The presence of progressive peripheral sensory-motor polyneuropathy and $\geq 1$ of the following red-flag signs and/or symptoms is suggestive of ATTR-FAP.

\section{Gastrointestinal symptoms}

Gastrointestinal symptoms such as nausea, early satiety, recurrent vomiting, watery diarrhea, severe constipation, and/or alternating diarrhea and constipation that occur as manifestations of autonomic neuropathy are documented early on in ATTR-FAP [1] and are the initial symptoms in nearly half of early-onset cases in endemic areas $[16,72,73]$. Patients from non-endemic areas mainly present with lower gastrointestinal tract symptoms such as diarrhea and/or constipation [20]. Notably, Japanese patients have an earlier onset of gastrointestinal disturbances than Swedish patients [74], making it an important red-flag symptom in Japanese patients.

\section{Carpal tunnel syndrome}

CTS is an early but non-specific orthopedic manifestation of ATTR-FAP. Often, ATTR-FAP patients are initially misdiagnosed with idiopathic CTS, and progressive symptoms or lack of improvement after release surgery often leads to the correct diagnosis. Therefore, CTS without obvious cause, particularly bilateral CTS that requires surgical release, should raise suspicion of ATTRFAP [1]. In a retrospective, observational study involving 76 Italian ATTR-FAP patients, CTS was an inaugural symptom in $33 \%$ patients, with no other clinical manifestations for a mean period of 4.6-5.6 years [75]. Likewise, in a study involving 31 Japanese patients diagnosed with systemic wild-type transthyretin amyloidosis at Shinshu University Hospital, CTS was the most common initial symptom, indicating that careful examination of patients with CTS may lead to earlier diagnosis [76].

\section{Unexplained weight loss}

Unintentional weight loss is frequently observed in ATTR-FAP patients because of gastrointestinal disturbances [1]. Cachexia is a major cause of death in earlyonset ATTR-FAP Val30Met patients from endemic foci in Japan and Portugal $[50,73,77]$.

\section{Autonomic dysfunction}

Although sensory and motor manifestations are generally presenting symptoms, autonomic dysfunction can be the first clinical presentation in early-onset cases [49]. In a nationwide survey conducted by the Study Group for Hereditary Neuropathy (under the auspices of the MHLW), autonomic dysfunction was the initial complaint in $48 \%$ of early-onset and $10 \%$ of late-onset cases [16]. Autonomic symptoms in late-onset ATTR-FAP are generally mild in the early phase of the disease [31]. However, autonomic dysfunction usually becomes apparent in the later phase of the disease, even in late-onset cases [20]. Further, as inadequate attention of neurologists to autonomic symptoms is a major diagnostic pitfall in ATTR-FAP, special attention must be paid to patients with concurrent autonomic dysfunction, CTS, and cardiac involvement $[1,19,31]$.

\section{Cardiac involvement}

Approximately $50 \%$ of patients with ATTR-FAP experience cardiac disease [1], and cardiac dysfunction is the major cause of death, particularly among patients from non-endemic areas [20,78]. Although signs and symptoms of cardiac disease generally appear in the later phase of ATTR-FAP, early assessments might reveal cardiac involvement [20]. Detection of subclinical cardiac involvement (e.g. cardiomegaly on chest X-ray, and thickening of the interventricular septum and granular sparkling on echocardiography [31]) may help diagnose late-onset ATTR-FAP Val30Met in patients without a family history of the disease [79]. Furthermore, detection of uptake of technetium-99m-pyrophosphate with cardiac scintigraphy 


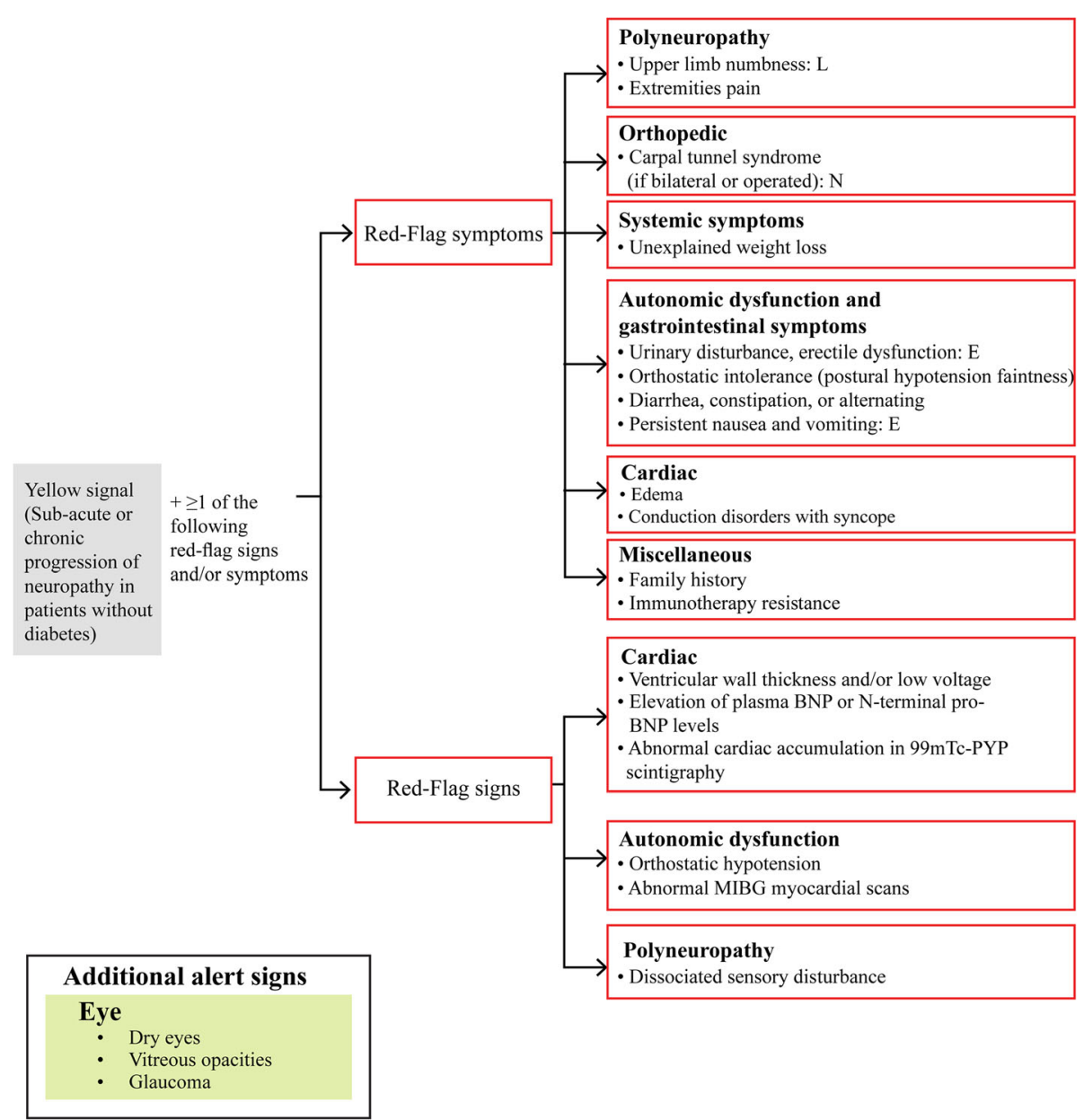

Fig. 3 Red-flag symptom clusters specific to ATTR-FAP Val30Met in Japan. E early-onset Val30Met, L late-onset Val30Met, N non-Val30Met, BNP brain natriuretic peptide, Tc-PYP Tc-pyrophosphate scintigraphy, MIBG metaiodobenzylguanidine

helps early diagnosis of TTR-cardiac amyloidosis with high sensitivity and specificity $[80,81]$.

\section{Family history}

In the aforementioned nationwide survey conducted in Japan, family history of ATTR-FAP Val30Met was found in $94 \%$ of early-onset and $48 \%$ of late-onset cases [16]. Despite a lower incidence of family history among patients with late-onset disease and those in non-endemic areas [16, 24, 79], red-flag symptom clusters should raise suspicion of ATTR-FAP, particularly in those with a family history. Further, experienced neurologists in endemic areas might possibly diagnose ATTR-FAP solely based on family history and clinical features $[1,46]$.

\section{Immunotherapy resistance}

Failure to respond to immunomodulatory treatment helps to differentiate ATTR-FAP from chronic inflammatory demyelinating polyneuropathy (CIDP), which is the most common misdiagnosis if associated with steady progression of the neuropathy, an axonal pattern, and autonomic dysfunction $[31,46]$.

The knowledge and awareness of the above red-flag symptom cluster among physicians in Japan may provide practical direction and promote early identification and diagnosis of the disease in this country.

\section{Diagnosis}

Diagnosis of ATTR-FAP involves two primary steps [82]:

1. Patient history and physical examination, which may raise clinical suspicion and permit a tentative diagnosis of ATTR-FAP

2. Confirmation using accurate diagnostic tools, including histopathology and genetic analysis (Fig. 4)

\section{Patient history and physical examination}

A thorough clinical history of the patient should be taken to identify the presence of family history and the multisystem red-flag signs and/or symptoms [1, 82]. In 


\begin{tabular}{|l|}
\hline \multicolumn{1}{|c|}{ DIAGNOSIS } \\
\hline Patient history and physical examination \\
- Family history of genetic disease \\
- Multisystem red-flag signs and/or symptoms \\
Confirmation using accurate diagnostic tools \\
- Histopathology \\
- Tissue biopsy of labial salivary gland, abdominal subcutaneous adipose tissue, gastrointestinal tract, and nerve tissue using Congo red \\
stain or TTR immunolabeling \\
- Immunohistochemistry \\
- Genetic testing (TTR genotyping) \\
- Targeted approach to detect pathogenic mutation in patients with a positive family history \\
- TRR gene sequencing may be required to detect suspected and new pathogenic mutations in patients without positive family history or \\
- with atypical symptoms \\
- Variant TTR protein levels using mass spectrometry \\
- Approximately 90\% of TTR variants identified using this method \\
- Amyloidogenic TTR mutations should be investigated ${ }^{2}$
\end{tabular}

\begin{tabular}{|c|c|}
\hline \multicolumn{2}{|c|}{ FOLLOW-UP EVALUATIONS } \\
\hline $\begin{array}{l}\text { Neurologic examination } \\
\text { - Electromyographic testing with sympathetic skin response } \\
\text { (SSR) } \\
\text { - Quantitative sensory testing } \\
\text { - Other autonomic tests } \\
\text { - Studies to assess progression } \\
\text { - Nerve conduction velocity } \\
\text { : Sensory action potentials } \\
\text { - Sotor action potentials } \\
\text { - Neurologitc disability score (NDS) } \\
\text { - Neuropathy impairment score (NIS Total) } \\
\text { - Quantitative sensory testing } \\
\text { Polyneuropathy disability (PND) score }\end{array}$ & $\begin{array}{l}\text { Cardiac evaluation } \\
\text { - Conduction disorders } \\
\text { E Electrocardiograms (ECG) } \\
\text { - Holter-(ECG) } \\
\text { - Infiltracardiac electrophysiology study } \\
\text { - ECG } \\
\text { - Echocardiomyopathy } \\
\text { BNP/troponin measurement } \\
\text { - Cardiac magnetic resonance } \\
\text { Ophthalmologic evaluation } \\
\text { Kidney evaluation } \\
\text { - Monitor proteinuria and renal function (creatinine clearance } \\
\text { and albuminuria) }\end{array}$ \\
\hline
\end{tabular}

Fig. 4 Diagnostic tools and follow-up evaluations for ATTR-FAP. BNP brain natriuretic peptide, ECG electrocardiogram, NDS neurologic disability score, NIS neuropathy impairment score, PND polyneuropathy disability, SSR sympathetic skin response, TTR transthyretin. ${ }^{a}$ Rowczenio DM, et al. 2014 [94]

the absence of a family history of amyloidosis, the diagnosis of ATTR-FAP should be considered in patients with a progressive, length-dependent, axonal polyneuropathy predominantly affecting temperature and pain sensation [1] (Fig. 4). After diagnosis, the modified body mass index (mBMI) as a measure of nutritional status is helpful to monitor progression or prognosis of ATTRFAP $[1,83]$.

\section{Histopathology}

Tissue biopsy: Demonstrating amyloid deposits via tissue biopsy is essential to confirm an ATTR-FAP diagnosis, especially in patients without a family history $[1,84,85]$. Tissue biopsy using Congo red stain [85] directly reveals amyloid deposits in affected tissues, including the labial salivary gland and abdominal subcutaneous adipose tissue, gastrointestinal tract, nerve tissue, and other organs with evidence of involvement [18, 31, 86-90]. TTR immunolabeling of amyloid deposits helps identify TTR amyloidosis [82] but does not aid differentiation between wild-type ATTR (ATTRwt) and mutant ATTR (ATTRm). Further, in the presence of typical signs and symptoms, negative biopsy results do not rule out ATTR-FAP [1] (Fig. 4).

\section{Genetic testing}

In patients with suspected ATTR-FAP, TTR genotyping should be performed to document the specific pathogenic TTR mutations; genotyping is the most reliable diagnostic approach, and absence of a pathogenic mutation excludes diagnosis of ATTR-FAP $[1,82]$. TTR genopositivity should be established by DNA analysis in all suspected cases [1, 30, 91-93]. In patients having family history with previous diagnosis, a targeted approach can be used to detect the pathogenic mutation. In the absence of family history and in patients with atypical symptoms, TTR gene sequencing may be required to detect suspected and new pathogenic mutations [35, 57]. Further, an online registry will prove useful to investigate amyloidogenic TTR mutations [94] (Fig. 4).

\section{Serum variant TTR protein}

TTR protein normally circulates in serum as a soluble protein with a tetrameric structure. The normal serum TTR concentration is 0.20 to $0.40 \mathrm{mg} / \mathrm{mL}$ ( 20 to $40 \mathrm{mg} /$ dL) $[57,95,96]$. After immunoprecipitation with antiTTR antibody and dissociation of the tetrameric structure of TTR (into pro-amyloidogenic monomers), serum 
variant TTR protein can be detected by mass spectrometry [97-100]. Approximately $90 \%$ of TTR variants are identified by this method and they exhibit the mass shift predicted by the one amino acid substitution of the variant TTR [57, 97, 101] (Fig. 4).

\section{Neurologic examination}

On the basis of presenting signs and symptoms, patients should undergo a complete neurological examination to identify, characterize, and measure the severity of neuropathic abnormalities involving small and large nerve fibers $[1,82]$. Scores used to assess neuropathy, and local variants and scales that quantify neurologic function in patients with diabetic polyneuropathy but are useful for patients with ATTR-FAP, should also be used to assess neuropathic symptoms [1]. Likewise, nerve conduction velocity, sensory action potentials, and other tests for characterizing small-fiber (coolness and heat detection) and large-fiber (vibratory detection) peripheral sensory thresholds should be used to evaluate ATTR-FAP progression [1] (Fig. 4).

Following diagnosis and assessment of neurological symptoms, systemic extension of the disease should be determined via assessment of heart, eyes, kidney, etc. [1, 82].

\section{Cardiac evaluation}

Cardiac investigations should be conducted to detect infiltrative cardiomyopathy and serious conduction disorders carrying risk of sudden death [1] (Fig. 4).

\section{Ophthalmologic evaluation}

Ophthalmological assessment is necessary to identify possible ocular manifestations such as keratoconjunctivitis sicca, secondary glaucoma, vitreous opacities, or pupillary abnormalities [69, 102] (Fig. 4).

\section{Kidney evaluation}

In view of possible microalbuminuria, and/or mild azotemias and subsequent renal failure, monitoring for proteinuria and abnormal renal function (creatinine clearance and albuminuria) parameters is recommended in ATTR-FAP patients [70, 82, 103].

\section{Common diagnostic pitfalls}

Though length-dependent sensory-motor polyneuropathy is a hallmark feature of ATTR-FAP, it is not distinctive of this condition and can be present in more prevalent neurological conditions, potentially leading to misdiagnoses [82, 92].

\section{CIDP}

CIDP, which is characterized by a demyelinating sensory-motor neuropathy, is the most common neuropathic misdiagnosis for sporadic ATTR-FAP. In one study, 53\% of 15 Japanese patients with sporadic ATTRFAP Val30Met were initially misdiagnosed with CIDP [31, 34]. Electrophysiological characteristics of ATTRFAP can resemble those of CIDP; however, no symptoms of autonomic dysfunction are present [30, 31]. Cerebrospinal fluid protein levels are elevated to a greater extent than those seen in ATTR-FAP [30, 92]. Also, a nerve biopsy revealing congophilic deposit differentiates ATTRFAP from CIDP [1]. ATTR-FAP should be suspected in patients diagnosed with CIDP that do not respond to immunomodulatory treatment if associated with steady progression of the neuropathy, an axonal pattern, and dysautonomia [30, 31, 46, 92].

\section{AL amyloidosis}

ATTR amyloidosis often was misdiagnosed as AL amyloidosis because of a high incidence of monoclonal gammopathy in elderly patients or false immunolabeling of amyloid deposits. However, this misdiagnosis can be avoided by careful typing of the amyloid precursor protein and genetic testing [1, 30, 91-93].

Other common misdiagnoses include idiopathic axonal polyneuropathy, other types of inherited sensory polyneuropathy, hereditary sensory and autonomic neuropathies, Fabry's disease, leprous neuropathy, mimicking neuropathies due to diabetes or chronic alcoholism, Charcot-Marie-Tooth neuropathy or motor neuron disease, lumbar spinal stenosis, anxiety, and vitamin B12 deficiency $[1,18,104]$.

\section{Management}

The management of ATTR-FAP involves three primary steps [82]:

1. Disease-modifying targeted therapy to prevent further production of amyloid deposits (e.g. LT, transthyretin kinetic stabilizers such as tafamidis, diflunisal) $[1,35]$

2. Symptomatic therapy of sensorimotor and autonomic polyneuropathy and cardiac, renal, and ocular injury $[1,35]$

3. Genetic counseling and supportive care $[1,105]$

Unlike European countries that have adopted pharmacotherapeutic treatment options for ATTR-FAP, LT remains first-line treatment in Japan [42, 106]. The Japan-specific ATTR-FAP treatment algorithm [107-109] developed at a medical advisory board meeting in Tokyo suggests that ATTR-FAP patients in Japan should initially be evaluated for presence of indications for LT. In patients who do not meet these indications, tafamidis should be administered. When indicated, patients should be further assessed for the presence of risk factors of cardiac dysfunction after LT. Patients without risk factors should 
undergo LT and be administered tafamidis until LT. Patients with risk factors may either undergo LT (tafamidis could be prescribed until transplantation) or may only be prescribed tafamidis (Fig. 5). Although ATTR-FAP disease duration $<5$ years is one of the indications for LT, some patients with mild symptoms, who meet other criteria may be considered for LT even if disease duration (from onset) is greater than 5 years $[56,110,111]$.

\section{$L T$}

Since 1990, LT has been the only potentially curative and disease-modifying treatment option for ATTR-FAP patients $[1,36-41]$. Serum TTR is mainly produced in the liver, and LT removes the primary source of mutant TTR, eliminates approximately $95 \%$ of variant TTR, and can slow or halt disease progression [1, 112-114]. A study that evaluated histopathological and biochemical characteristics of abdominal fat amyloid in patients who had undergone LT over 10 years earlier showed that tissue-deposited amyloid in FAP patients can gradually regress over the long term after LT [112]. Results from the Familial Amyloidotic Polyneuropathy World Transplant Registry (FAPWTR) initiated in 1995 show excellent patient survival (overall 5-year patient survival 77\%, 20 -year survival $55.3 \%$ ), which is comparable to the survival rates seen in LT performed for other chronic liver disorders $[33,115]$. The 20-year retrospective analysis by the FAPWTR also revealed that early disease onset, short disease duration, and the Val30Met mutation were significantly related to decreased mortality in LT patients $(p<0.001)$, while sex does not relate to increased survival for the early-onset LT patients $(p=0.442)$ [33]. A study of 80 consecutive patients with ATTR-FAP Val30Met who visited Kumamoto University hospital between January 1990 and December 2010 showed that Japanese patients undergoing LT have prolonged survival $(p<0.001)$ and higher $(100 \%$ vs $56.1 \%)$ estimated probability of survival at 10 years after the onset of FAP [116]. In early-onset disease, significantly $(p<0.001)$ improved survival is observed in transplanted patients as compared to non-transplanted cases. However, in lateonset disease, survival of transplanted patients does not differ from that of non-transplanted patients [108]. Also, while early-onset cases showed no significant difference in survival after LT between male and female patients, late-onset disease female transplanted patients had significantly $(p=0.02)$ improved survival than male transplanted cases [108]. It is also noteworthy that 10year survival rate after LT was numerically (but not significantly) better in patients who received a livingdonor liver graft than those who received a graft from a deceased donor $(72.3 \%$ vs $33.8 \%, p=0.092)$ [117]. Another study of 45 patients with symptomatic ATTR-FAP showed overall 1- and 5-year survival rates of $82 \%$ and $60 \%$, respectively, a marked reduction in circulating mutated TTR levels (2.5\% of pre-LT values), and a markedly lower rate of axonal degeneration $\left(0.9 / \mathrm{mm}^{2}\right.$ vs $70 / \mathrm{mm}^{2}$ of endoneurial area/month in transplanted vs non-

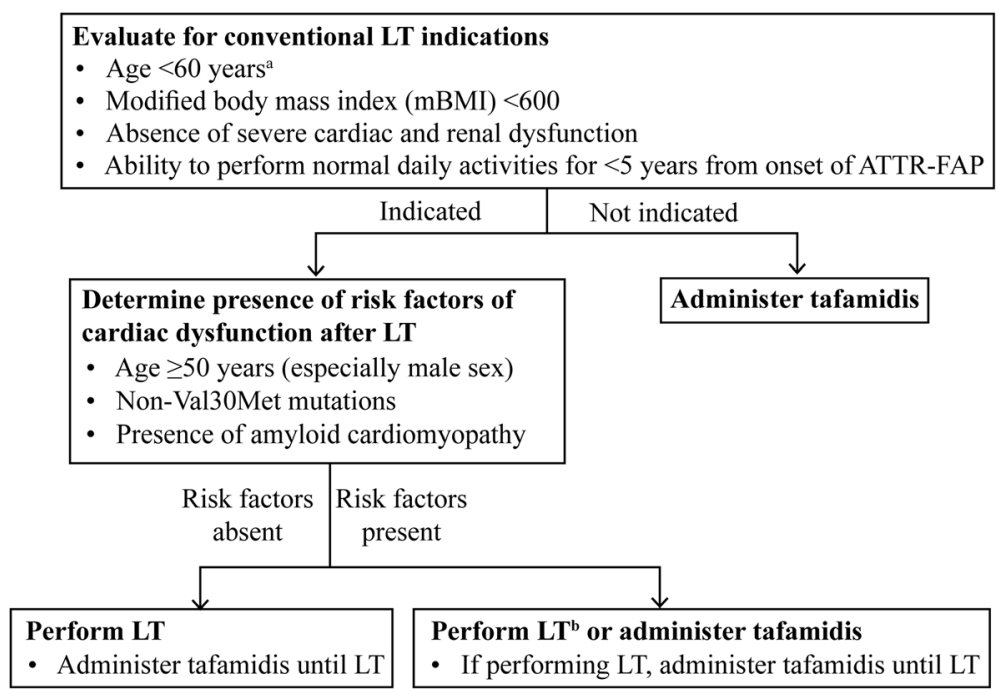

Fig. 5 Treatment algorithm specific to ATTR-FAP Val30Met in Japan. ${ }^{a}$ Most late-onset ATTR-FAP patients show progression of the disease even after LT. However, our experience in Japan and evidence in literature suggest a good outcome after LT in some of the late-onset patients; especially, late-onset females showed significantly improved survival after LT than their male counterparts ( $p=0.02$, Okamoto S, et al. 2009 [108]; hazard ratio 1.57 [male vs female, $p=0.014$ ], Ericzon BG, et al. 2015 [33]). ' Even in the late-onset cases, LT sometimes show good outcome in females (Ericzon BG, et al. 2015 [33]). The outcome of LT is comparably good in neuropathic type of non-Val30Met ATTR-FAP patients from our experience in Kumamoto University Hospital and Shinshu University Hospital in Japan (unpublished observations). LT liver transplantation, ATTR-FAP transthyretin familial amyloid neuropathy, Val30Met replacement of valine with methionine at position 30 in the TTR gene 
transplanted patients) after LT; LT at first symptom onset and exclusion of patients with a Norris score $<55$ and/or with urinary incontinence have been recommended [118]. Long-term survival after LT can be predicted by calculating the 5 -year risk of death from the polyneuropathy disability (PND) score, presence or absence of orthostatic hypotension, New York Heart Association (NYHA) functional class, QRS duration, and interventricular septal thickness [119].

Of note, the situation surrounding the use of LT for ATTR-FAP in Japan is different from that in other areas of the world. Liver tissue from live donors is used for LT in Japan, whereas cadaveric liver tissue is used elsewhere [1]. Consequently, better LT treatment outcomes, including higher survival rates post LT, are achieved in Japan [116]. Therefore, despite the use of a recently approved therapy tafamidis, which is a first-line treatment option for patients with early-stage ATTR-FAP in Europe [42], LT remains the first-line treatment option in Japan, especially for early-onset ATTR-FAP Val30Met [106].

Despite being a standard therapeutic strategy for ATTR-FAP, LT has several limitations [113]. Organ impairment occurring before LT is not reversed [1]. As seen in the FAPWTR, the outcomes of LT are mutationspecific (10-year survival rate is $74 \%$ for Val30Met vs $44 \%$ for non-Val30Met patients; 20 -year mortality rate in Val30Met patients is $61 \%$ that of non-Val30Met patients, $p<0.001)[1,33]$. Further, in some patients, disease progression occurs even after LT [62, 120]. For example, progression of cardiac amyloid infiltration continues post-LT because wild-type TTR continues to deposit on existing amyloid deposits [121-124]. Likewise, ocular and leptomeningeal deposits continue to increase after LT because of local, mutant TTR synthesis in the retinal epithelium and choroid plexus [61, 62, 113, 125-129]. Hence, although autonomic disturbances decrease post LT, nerve function rarely improves [1]. Also, in addition to the risks of surgery, long-term post-LT immunosuppressive therapy is required in these patients [1]. Further, many patients are not suitable candidates for LT, while in many others LT is not readily accessible $[82,130]$. In addition, the risk of acquired systemic TTR amyloidosis in patients receiving domino LT should not be underestimated [131].

\section{Pharmacotherapy}

As destabilization of the TTR-tetramer along with misfolding and fibril formation contribute to its proamyloidogenic potential, TTR-tetramer stabilization was identified as a rate-limiting step and several new pharmacologic therapies such as TTR stabilizing agents were evaluated for the treatment of ATTR-FAP. These can be prescribed at an early stage of disease in anticipation of LT or to potentially delay the need for LT [1].

\section{Tafamidis}

Tafamidis (Vyndaqel ${ }^{\circ}$; Pfizer Inc.) approved in Europe in 2011 [42] and in Japan in 2013 is the only prescription drug for ATTR-FAP [132]. In addition to improved diagnostic techniques, availability of tafamidis prompted earlier diagnosis of cases from non-endemic areas, as it marked the transformation of ATTR-FAP from an uncontrollable condition into a treatable disease entity. Tafamidis, a disease-modifying agent, kinetically stabilizes mutant TTR tetramers and prevents their dissociation into monomers, which is a critical, rate-limiting step in fibril formation and amyloidogenesis [1, 133-135]. In a randomized, double-blind trial, where early-stage ATTR-FAP patients received tafamidis meglumine $20 \mathrm{mg}$ (tafamidis $12.2 \mathrm{mg}$ ) once daily or placebo for 18 months, although no differences were observed between the tafamidis and placebo groups for the Neuropathy Impairment ScoreLower Limbs (NIS-LL) responder analysis ( $45.3 \%$ vs $29.5 \%$ responders; $p=0.068$ ) and change in Norfolk Quality of Life Diabetic Neuropathy total score (TQOL; 2.0 vs 7.2; $p=0.116)$ in the intent-to-treat population $(n=125)$, a significantly greater proportion $(60.0 \%$ vs $38.1 \%$; $p<$ 0.041) of patients receiving tafamidis were NIS-LL responders and tafamidis patients had better-preserved TQOL (0.1 vs $8.9 ; p=0.045)$ in the efficacy-evaluable population $(n=87)$. Additionally, patients on tafamidis had better-preserved TQOL $(0.1$ vs $8.9 ; p<0.045)$ and showed $52 \%$ less neurologic deterioration with adverse events (AEs) comparable to patients receiving placebo [32]. Another 12-month, open-label extension study that evaluated the long-term safety, tolerability, and efficacy of tafamidis $20 \mathrm{mg}$ once daily in 86 patients showed reduced rates of neurological deterioration in patients treated with tafamidis for 30 months. Further, patients treated for 30 months had $55.9 \%$ greater preservation of neurologic function (as measured by the NIS-LL) than those in whom tafamidis was initiated later, thus demonstrating that early initiation of tafamidis was required to slow disease progression. Urinary tract infection, diarrhea, thermal burn, and nasopharyngitis were some of the most commonly observed AEs in the tafamidis group. However, no new safety or tolerability concerns were identified and the overall incidence of AEs and serious AEs was similar between tafamidis and placebo groups [42, 136]. Furthermore, an ongoing long-term, open-label extension study has revealed that early treatment with tafamidis for up to 5.5 years sustainably delayed neurologic progression and preserved nutritional status (mean changes from baseline: NIS-LL, 5.3 points; $\mathrm{mBMI},-7.8 \mathrm{~kg} / \mathrm{m}^{2} \times \mathrm{g} / \mathrm{L}$ ), without any new safety concerns [137].

In Japan, the efficacy and safety of tafamidis meglumine $20 \mathrm{mg}$ (tafamidis $12.2 \mathrm{mg}$ ) once daily in ATTRFAP patients $(n=10$, male $70 \%$, mean age 60.1 years) 
were evaluated for 1.5 years in a phase III, single-arm, open-label study [138]. The majority had the Val30Met mutation (90\%) and were late-onset cases $(70 \%$, mean onset age 65.6 years). At week 8 of treatment, TTR stabilization was achieved in all the 10 patients (primary endpoint, percent stabilization $\geq 32 \%$ ) and maintained over week 78 in $8(80 \%)$ patients. Treatment with tafamidis delayed neuropathic progression (mean [SD] NISLL change at week 78, 3.3 [4.7]), maintained quality of life (mean [SD] TQOL change at week 78, 10.8 [13.7]) and improved nutritional status (mean [SD] mBMI increase at week 78, 53.7 [81.4]) over the study period. Nasopharyngitis, muscular weakness, bacterial pneumonia, and thermal burn were the most common AEs. Two AEs (gingival swelling and sudden death) in two patients were treatment-related, but no discontinuation due to AEs was observed [138]. These findings were consistent with previous tafamidis trials $[32,136]$ although generalizability is limited due to the small patient number and the non-comparative setting.

\section{Diflunisal}

Diflunisal, a generic nonsteroidal anti-inflammatory drug (NSAID), also slows the rate of amyloidogenesis by preventing the dissociation, misfolding, and misassembly of mutated TTR tetramers. Diflunisal preferentially stabilizes TTR tetramers by increasing the tetramer dissociation barrier via small molecule binding and by binding to the $99 \%$ unoccupied L-thyroxine binding sites in TTR $[139,140]$. Because of high serum concentrations after oral administration, diflunisal imposes kinetic stability on TTR heterotetramers exceeding that of the wild-type homotetramer and compensates for its modest binding affinity and selectivity to TTR over all other serum proteins. Thus, diflunisal is the most promising NSAID for the treatment of TTR amyloidosis [140]. Diflunisal administered at a dose of $250 \mathrm{mg}$ twice a day is sufficient to impose kinetic stabilization on the tetrameric native state of TTR and achieves kinetic stabilization under very demanding denaturing conditions. In an international randomized, double-blind, placebo-controlled study conducted among 130 ATTR-FAP patients in Sweden, Italy, Japan, England, and the United States from 2006 through 2012, polyneuropathy progression (measured by the Neuropathy Impairment Score plus 7 nerve tests $[\mathrm{NIS}+7]$ ) was significantly less (NIS+7 score: 8.7 [95\% confidence interval (CI), 3.3-14.1] vs 25.0 [95\% CI, 18.4-31.6]) in patients receiving diflunisal. Also, patients on diflunisal showed significant improvement in quality of life measures than patients on placebo in whom quality of life deteriorated. Further, a greater proportion of patients receiving diflunisal $(29.7 \%$ vs $9.4 \%)$ exhibited neurological stability at 2 years $(<2$-point increase in NIS +7 score; $p=0.007$ ) [141]. A retrospective analysis of off- label use of diflunisal in patients with ATTR-FAP reported treatment discontinuation in $57 \%$ of patients due to gastrointestinal side effects [142].

The contraindication for NSAIDs in patients with severe congestive heart failure (NYHA class IV) or renal insufficiency (estimated creatinine clearance $<30 \mathrm{~mL} / \mathrm{min}$ ) may limit its use in ATTR-FAP patients with cardiac or renal involvement [106, 141, 143]. Although the incidences of cardiac or renal events were similar in the diflunisal and placebo groups in a phase III study, two patients in the diflunisal group discontinued treatment due to gastrointestinal bleeding and congestive heart failure, respectively [141]. Because of risks of gastrointestinal bleeding, altered renal function, or fluid retention, patient selection, management of anti-inflammatory drug liabilities and long-term surveillance for AEs may be required $[1,139,144]$.

\section{Symptomatic therapy}

The immediate goal of ATTR-FAP management is to alleviate symptoms; therefore, symptomatic management of sensory-motor neuropathy and autonomic dysfunction should be initiated immediately after diagnosis, irrespective of presenting symptoms [1]. Symptomatic treatments include prophylactic pacemaker implantation to reduce major cardiac events; medications to treat cardiomyopathy, pain, diarrhea, orthostatic hypotension, urinary incontinence, hypothyroidism, and cardiac failure; erythropoietin or iron for anemia; CTS-release surgery; hemodialysis for renal failure; and vitrectomy or trabeculectomy for ocular amyloidosis $[1,82,145]$. In a 45-month study, prophylactic pacemaker implantation mitigated major cardiac events in patients with polyneuropathy and conduction disorders [146]. Likewise, in older ATTR-FAP patients with cardiomyopathy, stabilization of fluid balance with a goal of reduction in filling pressure was achieved with very low doses of loop diuretics [106, 147].

\section{Genetic counseling}

Considering that genetic testing is a major tool for diagnosis and that it helps carrier detection in a genetic-counseling setting, relatives should be strongly encouraged to undergo genetic testing and tissue biopsies (in cases of TTR genopositivity) [1, 34]. However, as genetic testing in patients with a family history of ATTR-FAP may lead to severe anxiety, genetic counseling and psychological support for patients and their family members is necessary $[1,34]$. Predictive genetic testing should be carried out in adult (aged $\geq 20$ ) relatives of ATTR-FAP patients, once they are able to understand the medical, social, and psychological outcomes of a positive genetic test [1]. Also, during genetic counseling, individuals with a 
positive result should be made aware of the disease's variable penetrance and the differences in age of symptom onset $[24,148,149]$.

\section{Supportive care}

As management of ATTR-FAP is extremely challenging, it is important to provide patients and their families with all the social and moral support possible. Efforts should be intensified to achieve early identification and diagnosis. Symptomatic treatment should be initiated immediately, and a long-term strategy should be devised. The FAPWTR [150] was established for collaboration and exchange of experience, monitoring international transplant activity, and optimization of patient selection, to ensure satisfactory follow-up after transplant and to serve as an exploratory research tool for treatment centers. Other country- and region-specific networks and centers of excellence also should be established for exchange of clinical, pathological, and genetic evidence, and sharing of expertise and best management practices [82].

\section{Emerging therapies}

A number of investigational pharmacologic treatments for ATTR-FAP are in development. Antisense oligonucleotide- and RNA interference-based therapeutics are two distinct methodologies aimed at reducing total TTR production [106]. ISIS-TTR $R_{R x}$ is an antisense oligonucleotide-based therapy that causes destruction of wild type and mutant TTR transcripts. Within 12 weeks of treatment, ISIS-TTR $R_{R x}$ treatment reduced hepatic TTR mRNA and serum TTR protein levels by $80 \%$ in mouse and non-human primate models $[151,152]$. Patisiran (ALN-TTR02) employs TTR-targeting, small interfering RNAs to reduce wild-type and mutant TTR. In a phase II, open-label, multidose, dose-escalation study involving 29 patients with stage I or II h-ATTRm amyloidosis with polyneuropathy, patisiran $0.3 \mathrm{mg} / \mathrm{kg}$ every 3 weeks resulted in a maximum mean reduction of $87 \%$ in TTR level; a maximum of $96 \%$ was attained in one patient [153]. Likewise, revusiran (ALN-TTRsc), a subcutaneously administered and TTR-targeting siRNA conjugated to a triantennary, reduced TTR protein expression by approximately $80 \%$ in non-human primate models at doses as low as $2.5 \mathrm{mg} / \mathrm{kg}$ [154].

Synergistic combination of doxycycline (an in vitro TTR fibril disrupter) and tauroursodeoxycholic acid (TUDCA; a biliary acid acting as a potent anti-apoptotic and anti-oxidant) has demonstrated removal of amyloid deposits in mouse models [155], and clinical trials (NCT01855360, NCT01171859) are seeking to replicate these findings in patients. Finally, endogenous and exogenous monoclonal antibodies can be used to target amyloid deposits $[106,156]$. A humanized, anti-amyloid, monoclonal antibody NEOD001 and the combination of a serum amyloid P depleter (GSK2315698) and an antiserum amyloid P monoclonal antibody (GSK2398852) are being tested in patients with various forms of amyloidosis (NCT01707264, NCT01777243).

\section{Conclusions}

Phenotypic and genetic heterogeneity may delay diagnosis of ATTR-FAP in Japan. The Japan-specific red-flag symptom clusters proposed herein may simplify diagnosis for physicians and prevent misdiagnosis or delayed diagnosis of ATTR-FAP. Likewise, our consensus-based ATTR-FAP treatment algorithm, which was also based on treatment outcomes observed in Japan, may guide clinicians regarding apt and judicious use of available treatment modalities.

\section{Abbreviations}

AE: Adverse event; ATTR: Transthyretin; ATTRwt: Wild-type transthyretin; $\mathrm{Cl}$ : Confidence interval; CIDP: Chronic inflammatory demyelinating polyneuropathy; CTS: Carpal tunnel syndrome; FAP: Familial amyloid polyneuropathy; FAPWTR: Familial Amyloidotic Polyneuropathy World Transplant Registry; h-ATTRm: hereditary transthyretin; LT: Liver transplantation; mBMl: modified body mass index; MHLW: Ministry of Health, Labour and Welfare, Japan; NIS+7: Neuropathy Impairment Score plus 7 nerve tests; NIS-LL: Neuropathy Impairment Score-Lower Limbs; NSAID: nonsteroidal anti-inflammatory drug; NYHA: New York Heart Association; PND: Polyneuropathy disability; TQOL: Norfolk Quality of Life Diabetic Neuropathy total score; TTR: Transthyretin;

TUDCA: Tauroursodeoxycholic acid; Val30Met: Replacement of valine with methionine at position 30

\section{Acknowledgements}

The authors would like to thank Dr. Laura Obici for her invaluable advice given to the medical advisory board meeting. Editorial support, in the form of medical writing, assembling tables and creating high-resolution images based on authors' detailed directions, collating author comments, copyediting, fact checking, and referencing, was provided by Dr. Alina Gomes, MD, and Maribeth Bogush, PhD, of Cactus Communications, and funded by Pfizer Japan.

Funding

Editorial assistance for this article and conduct of the medical advisory board meeting were funded by Pfizer, Japan.

\section{Availability of data and materials}

Data sharing is not applicable to this article as no datasets were generated or analyzed during the current study.

\section{Authors' contributions}

All named authors meet the International Committee of Medical Journal Editors (ICMJE) criteria for authorship, take responsibility for the integrity of the work as a whole, and have given final approval for the version to be published.

\section{Ethics approval and consent to participate} Not applicable.

\section{Consent for publication}

Not applicable.

\section{Competing interests}

YS, MU, HK, SM, and YA declare receipt of consulting fee or honorarium, support for travel to meetings, and provision for writing assistance from Pfizer Japan Inc. TI is employed by and has stock ownership in Pfizer Japan Inc. 


\section{Publisher's Note}

Springer Nature remains neutral with regard to jurisdictional claims in published maps and institutional affiliations.

\begin{abstract}
Author details
${ }^{1}$ Department of Medicine (Neurology and Rheumatology), Shinshu University School of Medicine, Matsumoto, Japan. ${ }^{2}$ Department of Neurology, Graduate School of Medical Sciences, Kumamoto University, 1-1-1 Honjo, Chuo-ku, Kumamoto-shi, Kumamoto 860-8556, Japan. ${ }^{3}$ Department of Neurology, Nagoya University Graduate School of Medicine, Nagoya, Japan. ${ }^{4}$ Department of Neurology, Graduate School of Medicine, Chiba University, Chiba, Japan. ${ }^{5}$ Pfizer Japan Inc., Tokyo, Japan.
\end{abstract}

Received: 31 July 2017 Accepted: 23 November 2017

Published online: 17 January 2018

\section{References}

1. Ando Y, Coelho T, Berk JL, Cruz MW, Ericzon BG, Ikeda S, Lewis WD, Obici L, Planté-Bordeneuve $V$, Rapezzi $C$, et al. Guideline of transthyretin-related hereditary amyloidosis for clinicians. Orphanet J Rare Dis. 2013;8:31.

2. Benson MD, Kincaid JC. The molecular biology and clinical features of amyloid neuropathy. Muscle Nerve. 2007:36:411-23.

3. Kato-Motozaki Y, Ono K, Shima K, Morinaga A, Machiya T, Nozaki I, ShibataHamaguchi A, Furukawa Y, Yanase D, Ishida C, et al. Epidemiology of familial amyloid polyneuropathy in Japan: identification of a novel endemic focus. J Neurol Sci. 2008:270:133-40.

4. Alemi M, Gaiteiro C, Ribeiro CA, Santos LM, Gomes JR, Oliveira SM, Couraud PO, Weksler B, Romero I, Saraiva MJ, et al. Transthyretin participates in betaamyloid transport from the brain to the liver-involvement of the lowdensity lipoprotein receptor-related protein 1? Sci Rep. 2016;6:20164.

5. Cavallaro T, Martone RL, Dwork AJ, Schon EA, Herbert J. The retinal pigment epithelium is the unique site of transthyretin synthesis in the rat eye. Invest Ophthalmol Vis Sci. 1990;31:497-501.

6. Herbert J, Wilcox JN, Pham KT, Fremeau RT Jr, Zeviani M, Dwork A, Soprano DR, Makover A, Goodman DS, Zimmerman EA, et al. Transthyretin: a choroid plexus-specific transport protein in human brain. The 1986 S. Weir Mitchell award. Neurology. 1986;36:900-11.

7. Jacobsson B, Collins VP, Grimelius L, Pettersson T, Sandstedt B, Carlstrom A. Transthyretin immunoreactivity in human and porcine liver, choroid plexus, and pancreatic islets. J Histochem Cytochem 1989;37:31-7.

8. Richardson SJ, Wijayagunaratne RC, D'Souza DG, Darras VM, Van Herck SL. Transport of thyroid hormones via the choroid plexus into the brain: the roles of transthyretin and thyroid hormone transmembrane transporters. Front Neurosci. 2015:9:66

9. Schreiber G, Aldred AR, Jaworowski A, Nilsson C, Achen MG, Segal MB Thyroxine transport from blood to brain via transthyretin synthesis in choroid plexus. Am J Phys. 1990;258:R338-45.

10. Ohmori H, Ando Y, Makita Y, Onouchi Y, Nakajima T, Saraiva MJ, Terazaki H, Suhr O, Sobue G, Nakamura M, et al. Common origin of the Val30Met mutation responsible for the amyloidogenic transthyretin type of familial amyloidotic polyneuropathy. J Med Genet. 2004;41:e51.

11. Hou X, Aguilar MI, Small DH. Transthyretin and familial amyloidotic polyneuropathy. Recent progress in understanding the molecular mechanism of neurodegeneration. FEBS J. 2007;274:1637-50.

12. Brito RMM, Damas AM, Saraiva MJ. Amyloid formation by transthyretin: from protein stability to protein aggregation. Curr Med Chem - Immun, Endoc \& Metab Agents. 2003;3:349-60

13. Ihse E, Rapezzi C, Merlini G, Benson MD, Ando Y, Suhr OB, Ikeda S, Lavatelli F, Obici L, Quarta CC, et al. Amyloid fibrils containing fragmented ATTR may be the standard fibril composition in ATTR amyloidosis. Amyloid. 2013;20:142-50

14. Takahashi K, Yi S, Kimura Y, Araki S. Familial amyloidotic polyneuropathy type 1 in Kumamoto, Japan: a clinicopathologic, histochemical, immunohistochemical, and ultrastructural study. Hum Pathol. 1991;22:519-27.

15. Koike H, Misu K, Sugiura M, lijima M, Mori K, Yamamoto M, Hattori N, Mukai E, Ando Y, Ikeda S, et al. Pathology of early- vs late-onset TTR Met30 familial amyloid polyneuropathy. Neurology. 2004;63:129-38.

16. Koike H, Misu K, Ikeda S, Ando Y, Nakazato M, Ando E, Yamamoto M, Hattori N, Sobue G. Type I (transthyretin Met30) familial amyloid polyneuropathy in Japan: early- vs late-onset form. Arch Neurol. 2002;59:1771-6.
17. Takahashi K, Sakashita N, Ando Y, Suga M, Ando M. Late onset type I familial amyloidotic polyneuropathy: presentation of three autopsy cases in comparison with 19 autopsy cases of the ordinary type. Pathol Int. 1997;47:353-9.

18. Adams D, Lozeron P, Lacroix C. Amyloid neuropathies. Curr Opin Neurol. 2012;25:564-72.

19. Dohrn MF, Röcken C, De Bleecker JL, Martin JJ, Vorgerd M, Van den Bergh PY, Ferbert A, Hinderhofer K, Schröder JM, Weis J, et al. Diagnostic hallmarks and pitfalls in late-onset progressive transthyretin-related amyloidneuropathy. J Neurol. 2013;260:3093-108.

20. Koike H, Tanaka F, Hashimoto R, Tomita M, Kawagashira Y, lijima M, Fujitake J, Kawanami T, Kato T, Yamamoto M, et al. Natural history of transthyretin Val30Met familial amyloid polyneuropathy: analysis of late-onset cases from non-endemic areas. J Neurol Neurosurg Psychiatry. 2012;83:152-8.

21. Mariani LL, Lozeron $P$, Théaudin M, Mincheva Z, Signate A, Ducot B, Algalarrondo V, Denier C, Adam C, Nicolas G, et al. Genotype-phenotype correlation and course of transthyretin familial amyloid polyneuropathies in France. Ann Neurol. 2015;78:901-16.

22. Araki S, Mawatari S, Ohta M, Nakajima A, Kuroiwa Y. Polyneuritic amyloidosis in a Japanese family. Arch Neurol. 1968;18:593-602.

23. Kito S, Itoga E, Kamiya K, Kishida T, Yamamura Y. Studies on familial amyloid polyneuropathy in Ogawa Village, Japan. Eur Neurol. 1980;19:141-51.

24. Misu K, Hattori N, Nagamatsu M, Ikeda S, Ando Y, Nakazato M, Takei Y, Hanyu N, Usui Y, Tanaka F, et al. Late-onset familial amyloid polyneuropathy type I (transthyretin Met30-associated familial amyloid polyneuropathy) unrelated to endemic focus in Japan. Clinicopathological and genetic features. Brain. 1999;122(Pt 10):1951-62.

25. Holmgren G, Costa PM, Andersson C, Asplund K, Steen L, Beckman L, Nylander PO, Teixeira A, Saraiva MJ, Costa PP. Geographical distribution of TTR met30 carriers in northern Sweden: discrepancy between carrier frequency and prevalence rate. J Med Genet. 1994;31:351-4.

26. Sousa A, Andersson R, Drugge U, Holmgren G, Sandgren O. Familial amyloidotic polyneuropathy in Sweden: geographical distribution, age of onset, and prevalence. Hum Hered. 1993:43:288-94.

27. Sousa A, Coelho T, Barros J, Sequeiros J. Genetic epidemiology of familial amyloidotic polyneuropathy (FAP)-type I in Póvoa do Varzim and Vila do Conde (north of Portugal). Am J Med Genet. 1995;60:512-21.

28. Cappellari M, Cavallaro T, Ferrarini M, Cabrini I, Taioli F, Ferrari S, Merlini G, Obici L, Briani C, Fabrizi GM. Variable presentations of TTR-related familial amyloid polyneuropathy in seventeen patients. J Peripher Nerv Syst. 2011;16:119-29.

29. Parman Y, Adams D, Obici L, Galan L, Guergueltcheva V, Suhr OB, Coelho T. Sixty years of transthyretin familial amyloid polyneuropathy (TTR-FAP) in Europe: where are we now? A European network approach to defining the epidemiology and management patterns for TTR-FAP. Curr Opin Neurol. 2016;29(Suppl 1):S3-S13.

30. Planté-Bordeneuve V, Ferreira A, Lalu T, Zaros C, Lacroix C, Adams D, Said G, Diagnostic pitfalls in sporadic transthyretin familial amyloid polyneuropathy (TTR-FAP). Neurology. 2007;69:693-8.

31. Koike H, Hashimoto R, Tomita M, Kawagashira Y, lijima M, Tanaka F, Sobue G. Diagnosis of sporadic transthyretin Val30Met familial amyloid polyneuropathy: a practical analysis. Amyloid. 2011;18:53-62.

32. Coelho T, Maia LF, Martins da Silva A, Waddington Cruz M, PlantéBordeneuve V, Lozeron P, Suhr OB, Campistol JM, Conceição IM, Schmidt $\mathrm{HH}$, et al. Tafamidis for transthyretin familial amyloid polyneuropathy: a randomized, controlled trial. Neurology. 2012;79:785-92.

33. Ericzon BG, Wilczek HE, Larsson M, Wijayatunga P, Stangou A, Pena JR, Furtado E, Barroso E, Daniel J, Samuel D, et al. Liver transplantation for hereditary transthyretin amyloidosis: after 20 years still the best therapeutic alternative? Transplantation. 2015:99:1847-54

34. Planté-Bordeneuve $\mathrm{V}$. Update in the diagnosis and management of transthyretin familial amyloid polyneuropathy. J Neurol. 2014;261:1227-33.

35. Adams D, Théaudin M, Cauquil C, Algalarrondo V, Slama M. FAP neuropathy and emerging treatments. Curr Neurol Neurosci Rep. 2014;14:435.

36. Holmgren G, Steen L, Ekstedt J, Groth CG, Ericzon BG, Eriksson S, Andersen O, Karlberg I, Nordén G, Nakazato M, et al. Biochemical effect of liver transplantation in two Swedish patients with familial amyloidotic polyneuropathy (FAP-met30). Clin Genet. 1991;40:242-6.

37. Ikeda S, Takei Y, Yanagisawa N, Matsunami H, Hashikura Y, Ikegami T, Kawasaki S. Peripheral nerves regenerated in familial amyloid polyneuropathy after liver transplantation. Ann Intern Med. 1997;127:618-20. 
38. Ando Y, Tanaka Y, Ando E, Yamashita T, Nishida Y, Tashima K, Suga M, Uchino M, Ando M. Effect of liver transplantation on autonomic dysfunction in familial amyloidotic polyneuropathy type I. Lancet. 1995;345:195-6.

39. Okumura K, Yamashita T, Masuda T, Misumi Y, Ueda A, Ueda M, Obayashi K, Jono $\mathrm{H}$, Yamashita S, Inomata $Y$, et al. Long-term outcome of patients with hereditary transthyretin V30M amyloidosis with polyneuropathy after liver transplantation. Amyloid. 2016;23:39-45.

40. Huang G, Ueda M, Tasaki M, Yamashita T, Misumi Y, Masuda T, Suenaga G, Inoue $Y$, Kinoshita $Y$, Matsumoto S, et al. Clinicopathological and biochemical findings of thyroid amyloid in hereditary transthyretin amyloidosis with and without liver transplantation. Amyloid. 2017;24:24-9.

41. Yamashita T, Ando Y, Ueda M, Nakamura M, Okamoto S, Zeledon ME, Hirahara T, Hirai T, Ueda A, Misumi Y, et al. Effect of liver transplantation on transthyretin Tyr114Cys-related cerebral amyloid angiopathy. Neurology. 2008;70:123-8.

42. Waddington Cruz M, Benson MD. A review of tafamidis for the treatment of transthyretin-related amyloidosis. Neurol Ther. 2015;4:61-79.

43. Misu K, Hattori N, Ando Y, Ikeda S, Sobue G. Anticipation in early- but not late-onset familial amyloid polyneuropathy (TTR met 30) in Japan. Neurology. 2000;55:451-2.

44. Koike H, Ikeda S, Takahashi M, Kawagashira Y, lijima M, Misumi Y, Ando Y, Ikeda SI, Katsuno M, Sobue G. Schwann cell and endothelial cell damage in transthyretin familial amyloid polyneuropathy. Neurology. 2016;87:2220-9.

45. Koike H, Kawagashira Y, lijima M, Yamamoto M, Hattori N, Tanaka F, Hirayama M, Ando Y, Ikeda S, Sobue G. Electrophysiological features of late-onset transthyretin Met30 familial amyloid polyneuropathy unrelated to endemic foci. J Neurol. 2008;255:1526-33.

46. Conceição I, González-Duarte A, Obici L, Schmidt HH, Simoneau D, Ong ML, Amass L. "Red-flag" symptom clusters in transthyretin familial amyloid polyneuropathy. J Peripher Nerv Syst. 2016;21:5-9.

47. Ikeda S. Is familial amyloid polyneuropathy rare? DNA testing is changing the concept of this disease. Neurology. 2007;69:627-8.

48. Ando Y, Araki S, Ando M. Transthyretin and familial amyloidotic polyneuropathy. Intern Med. 1993;32:920-2.

49. Ando Y, Suhr OB. Autonomic dysfunction in familial amyloidotic polyneuropathy (FAP). Amyloid. 1998:5:288-300.

50. Andrade CA. Peculiar form of peripheral neuropathy; familiar atypical generalized amyloidosis with special involvement of the peripheral nerves. Brain. 1952;75:408-27.

51. Araki S. Type I familial amyloidotic polyneuropathy (Japanese type). Brain Dev. 1984;6:128-33.

52. Ando $Y$, Nakamura M, Araki S. Transthyretin-related familial amyloidotic polyneuropathy. Arch Neurol. 2005;62:1057-62

53. Ikeda S, Hanyu N, Hongo M, Yoshioka J, Oguchi H, Yanagisawa N, Kobayashi T, Tsukagoshi H, Ito N, Yokota T. Hereditary generalized amyloidosis with polyneuropathy. Clinicopathological study of 65 Japanese patients. Brain. 1987;110(Pt 2):315-37.

54. Nakazato M, Shiomi K, Miyazato M, Matsukura S. Type I familial amyloidotic polyneuropathy in Japan. Intern Med. 1992;31:1335-8.

55. Sobue G, Koike H, Misu K, Hattori N, Yamamoto M, Ikeda S, Ando Y, Nakazato $\mathrm{M}$, Inukai A. Clinicopathologic and genetic features of early- and late-onset FAP type I (FAP ATTR Val30Met) in Japan. Amyloid. 2003;10(Suppl 1):32-8.

56. Yamamoto K, Ikeda S, Hanyu N, Takeda S, Yanagisawa N. A pedigree analysis with minimised ascertainment bias shows anticipation in Met30-transthyretin related familial amyloid polyneuropathy. J Med Genet. 1998;35:23-30.

57. Sekijima Y, Yoshida K, Tokuda T, Ikeda S. Familial transthyretin amyloidosis. In: GeneReviews. Seattle (WA): University of Washington, Seattle. 1993-2017. https://www.ncbi.nlm.nih.gov/books/NBK1194/. Accessed 14 Apr 2017.

58. Obayashi K, Ando Y, Nakamura M, Yamashita T, Ueda M, Haraoka K, Terazaki $\mathrm{H}$, Uchino M. Near-infrared spectrophotoscopy of finger venules in assessment of autonomic dysfunction. Neurology. 2004;63:164-6.

59. Koike H, Morozumi S, Kawagashira Y, lijima M, Yamamoto M, Hattori N, Tanaka F, Nakamura T, Hirayama M, Ando Y, et al. The significance of carpal tunnel syndrome in transthyretin Val30Met familial amyloid polyneuropathy. Amyloid. 2009;16:142-8.

60. Ikeda S. Clinical picture and outcome of transthyretin-related familial amyloid polyneuropathy (FAP) in Japanese patients. Clin Chem Lab Med. 2002:40:1257-61

61. Maia LF, Magalhães R, Freitas J, Taipa R, Pires MM, Osório H, et al. CNS involvement in V30M transthyretin amyloidosis: clinical, neuropathological and biochemical findings. J Neurol Neurosurg Psychiatry. 2015;86:159-67.
62. Sekijima Y, Yazaki M, Oguchi K, Ezawa N, Yoshinaga T, Yamada M, et al. Cerebral amyloid angiopathy in posttransplant patients with hereditary ATTR amyloidosis. Neurology. 2016;87:773-81.

63. Koike H, Ando Y, Ueda M, Kawagashira Y, lijima M, Fujitake J, et al. Distinct characteristics of amyloid deposits in early- and late-onset transthyretin Val30Met familial amyloid polyneuropathy. J Neurol Sci. 2009;287:178-84.

64. Nakamura M, Yamashita T, Ueda M, Obayashi K, Sato T, Ikeda T, Washimi Y, Hirai T, Kuwahara Y, Yamamoto MT, et al. Neuroradiologic and clinicopathologic features of oculoleptomeningeal type amyloidosis. Neurology. 2005;65:1051-6.

65. Ueda M, Ando Y, Haraoka K, Katsuragi S, Terasaki Y, Sugimoto M, Sun X, Uchino M. Aging and transthyretin-related amyloidosis: pathologic examinations in pulmonary amyloidosis. Amyloid. 2006;13:24-30.

66. Haraoka K, Ando Y, Ando E, Sandgren O, Hirata A, Nakamura M, Terazaki H, Tajiri $T$, Tanoue $Y$, Sun $X$, et al. Amyloid deposition in ocular tissues of patients with familial amyloidotic polyneuropathy (FAP). Amyloid. 2002;9:183-9.

67. Mitsuhashi S, Yazaki M, Tokuda T, Sekijima Y, Washimi Y, Shimizu Y, Ando Y, Benson MD, Ikeda S. Biochemical characteristics of variant transthyretins causing hereditary leptomeningeal amyloidosis. Amyloid. 2005;12:216-25.

68. Elliott $P$, Andersson B, Arbustini E, Bilinska Z, Cecchi F, Charron P, Dubourg O, Kühl U, Maisch B, McKenna WJ, et al. Classification of the cardiomyopathies: a position statement from the European Society of Cardiology Working Group on myocardial and pericardial diseases. Eur Heart J. 2008;29:270-6.

69. Ando E, Ando Y, Okamura R, Uchino M, Ando M, Negi A. Ocular manifestations of familial amyloidotic polyneuropathy type I: long-term follow up. Br J Ophthalmol. 1997:81:295-8.

70. Lobato L, Rocha A. Transthyretin amyloidosis and the kidney. Clin J Am Soc Nephrol. 2012;7:1337-46.

71. Beirão I, Lobato L, Costa PM, Fonseca I, Mendes P, Silva M, Bravo F, Cabrita A, Porto G. Kidney and anemia in familial amyloidosis type I. Kidney Int. 2004;66:2004-9.

72. Araki S, Kurihara T, Tawara S, Kuribayashi T. Familial amyloidotic polyneuropathy in Japanese. In: Glenner GG, Pinho a Costa P, de Freitas F, editors. Amyloid and amyloidosis. Amsterdam: Excerpta Medica; 1980. p. $67-77$.

73. Coutinho P, Martins da Silva A, Lopes Lima J, Resende Barbosa A. Forty years of experience with type I amyloid neuropathy. Review of 483 cases. In: Glenner GG, Pinho a Costa P, de Freitas F, editors. Amyloid and amyloidosis. Amsterdam: Excerpta Medica; 1980. p. 88-98.

74. Tashima K, Suhr OB, Ando Y, Holmgren G, Yamashita T, Obayashi K, Terazaki $H$, Uchino M. Gastrointestinal dysfunction in familial amyloidotic polyneuropathy (ATTR Val30Met) — comparison of Swedish and Japanese patients. Amyloid. 1999;6:124-9.

75. Mazzeo A, Russo M, Di Bella G, Minutoli F, Stancenelli C, Gentile L, Toscano A, Vita G. TTR-FAP: a single-center experience in Sicily, an Italian endemic area. Orphanet J Rare Dis. 2015;10(Suppl 1):01

76. Nakagawa M, Sekijima Y, Yazaki M, Tojo K, Yoshinaga T, Doden T, Koyama J, Yanagisawa S, Ikeda S. Carpal tunnel syndrome: a common initial symptom of systemic wild-type ATTR (ATTRwt) amyloidosis. Amyloid. 2016;23:58-63.

77. Ikegawa S, Araki S, Nagata J, Takaba Y, Nakashima A. Review of clinical records and therapeutic trials to familial amyloidotic polyneuropathy-study of 50 cases in Kumamoto (1967-1984). Rinsho Shinkeigaku 1986;26:175-9. [Article in Japanese].

78. Ikeda S. Cardiac amyloidosis: heterogenous pathogenic backgrounds. Intern Med. 2004:43:1107-14.

79. Koike H, Sobue G. Diagnosis of familial amyloid polyneuropathy: wideranged clinicopathological features. Expert Opin Med Diagn. 2010;4:323-31.

80. Hongo M, Hirayama J, Fujii T, Yamada H, Okubo S, Kusama S, et al. Early identification of amyloid heart disease by technetium-99m-pyrophosphate scintigraphy: a study with familial amyloid polyneuropathy. Am Heart J. 1987;113:654-62.

81. Bokhari S, Castano A, Pozniakoff T, Deslisle S, Latif F, Maurer MS. (99m)Tcpyrophosphate scintigraphy for differentiating light-chain cardiac amyloidosis from the transthyretin-related familial and senile cardiac amyloidoses. Circ Cardiovasc Imaging. 2013;6:195-201.

82. Adams D, Suhr OB, Hund E, Obici L, Tournev I, Campistol JM, Slama MS, Hazenberg BP, Coelho T. First European consensus for diagnosis, management, and treatment of transthyretin familial amyloid polyneuropathy. Curr Opin Neurol. 2016;29(Suppl 1):S14-26. 
83. Suhr O, Danielsson A, Holmgren G, Steen L. Malnutrition and gastrointestinal dysfunction as prognostic factors for survival in familial amyloidotic polyneuropathy. J Intern Med. 1994;235:479-85.

84. Guy CD, Jones CK. Abdominal fat pad aspiration biopsy for tissue confirmation of systemic amyloidosis: specificity, positive predictive value, and diagnostic pitfalls. Diagn Cytopathol. 2001;24:181-5.

85. Vital C, Vital A, Bouillot-Eimer S, Brechenmacher C, Ferrer X, Lagueny A. Amyloid neuropathy: a retrospective study of 35 peripheral nerve biopsies J Peripher Nerv Syst. 2004;9:232-41.

86. Do Amaral B, Coelho T, Sousa A, Guimarães A. Usefulness of labial salivary gland biopsy in familial amyloid polyneuropathy Portuguese type. Amyloid. 2009;16:232-8.

87. Kyle RA, Spencer RJ, Dahlin DC. Value of rectal biopsy in the diagnosis of primary systemic amyloidosis. Am J Med Sci. 1966;251:501-6.

88. Picken MM, Westermark P. Amyloid detection and typing: summary of current practice and recommendations of the consensus group. Amyloid. 2011:18(Suppl 1):48-50.

89. Röcken C, Sletten K. Amyloid in surgical pathology. Virchows Arch. 2003;443:3-16.

90. Westermark P. Subcutaneous adipose tissue biopsy for amyloid protein studies. Methods Mol Biol. 2012;849:363-71.

91. Briani C, Cavallaro T, Ferrari S, Taioli F, Calamelli S, Verga L, Adami F, Fabrizi GM. Sporadic transthyretin amyloidosis with a novel TTR gene mutation misdiagnosed as primary amyloidosis. J Neurol. 2012;259:2226-8.

92. Conceição I, De Carvalho M. Clinical variability in type I familial amyloid polyneuropathy (Val30Met): comparison between late- and early-onset cases in Portugal. Muscle Nerve. 2007;35:116-8.

93. Cowan AJ, Skinner M, Berk JL, Sloan JM, O'hara C, Seldin DC, Sanchorawala V. Macroglossia - not always AL amyloidosis. Amyloid. 2011;18:83-6.

94. Rowczenio DM, Noor I, Gillmore JD, Lachmann HJ, Whelan C, Hawkins $\mathrm{PN}$, et al. Online registry for mutations in hereditary amyloidosis including nomenclature recommendations. Hum Mutat. 2014:35:E2403-12.

95. Kelly JW. The alternative conformations of amyloidogenic proteins and their multi-step assembly pathways. Curr Opin Struct Biol. 1998:8:101-6.

96. Rochet JC, Lansbury PT Jr. Amyloid fibrillogenesis: themes and variations. Curr Opin Struct Biol. 2000;10:60-8.

97. Tachibana N, Tokuda T, Yoshida K, Taketomi T, Nakazato M, Li YF, Masuda Y, Ikeda S. Usefulness of MALDI/TOF mass spectrometry of immunoprecipitated serum variant transthyretin in the diagnosis of familial amyloid polyneuropathy. Amyloid. 1999;6:282-8.

98. Ando Y, Ohlsson Pl, Suhr O, Nyhlin N, Yamashita T, Holmgren G, Danielsson A, Sandgren O, Uchino M, Ando M. A new simple and rapid screening method for variant transthyretin-related amyloidosis. Biochem Biophys Res Commun. 1996;228:480-3.

99. Ueda M, Misumi Y, Mizuguchi M, Nakamura M, Yamashita T, Sekijima Y, Ota $\mathrm{K}$, Shinriki S, Jono H, Ikeda S, et al. SELDI-TOF mass spectrometry evaluation of variant transthyretins for diagnosis and pathogenesis of familial amyloidotic polyneuropathy. Clin Chem. 2009;55:1223-7.

100. Tasaki M, Ueda M, Obayashi K, Koike H, Kitagawa K, Ogi Y, Jono H, Su Y, Suenaga G, Oshima T, et al. Effect of age and sex differences on wild-type transthyretin amyloid formation in familial amyloidotic polyneuropathy: a proteomic approach. Int J Cardiol. 2013;170:69-74.

101. Connors LH, Lim A, Prokaeva T, Roskens VA, Costello CE. Tabulation of human transthyretin (TTR) variants, 2003. Amyloid. 2003;10:160-84.

102. Rousseau A, Kaswin G, Adams D, Cauquil C, Théaudin M, Mincheva Z, M'garrech M, Labetoulle M, Barreau E. Ocular involvement in familial amyloid polyneuropathy. J Fr Ophtalmol. 2013;36:779-88.

103. Lobato L, Beirão I, Silva M, Bravo F, Silvestre F, Guimarães S, Sousa A, Noël $\mathrm{LH}$, Sequeiros J. Familial ATTR amyloidosis: microalbuminuria as a predictor of symptomatic disease and clinical nephropathy. Nephrol Dial Transplant. 2003;18:532-8

104. Adams D, Lozeron P, Theaudin M, Mincheva Z, Cauquil C, Adam C, Signate $A$, Vial C, Maisonobe T, Delmont E, et al. Regional difference and similarity of familial amyloidosis with polyneuropathy in France. Amyloid. 2012; 19(Suppl 1):61-4.

105. Obici L, Kuks JB, Buades J, Adams D, Suhr OB, Coelho T, Kyriakides T. Recommendations for presymptomatic genetic testing and management of individuals at risk for hereditary transthyretin amyloidosis. Curr Opin Neurol. 2016;29(Suppl 1):S27-35
106. Hawkins PN, Ando Y, Dispenzeri A, Gonzalez-Duarte A, Adams D, Suhr OB. Evolving landscape in the management of transthyretin amyloidosis. Ann Med. 2015;47:625-38.

107. Ohya Y, Okamoto S, Tasaki M, Ueda M, Jono H, Obayashi K, Takeda K, Okajima H, Asonuma K, Hara R, et al. Manifestations of transthyretinrelated familial amyloidotic polyneuropathy: long-term follow-up of Japanese patients after liver transplantation. Surg Today. 2011:41:1211-8.

108. Okamoto S, Wixner J, Obayashi K, Ando Y, Ericzon BG, Friman S, Uchino M, Suhr OB. Liver transplantation for familial amyloidotic polyneuropathy: impact on Swedish patients' survival. Liver Transpl. 2009;15:1229-35.

109. Yamamoto S, Wilczek HE, Nowak G, Larsson M, Oksanen A, Iwata T, Gjertsen H, Soderdahl G, Wikstrom L, Ando Y, et al. Liver transplantation for familial amyloidotic polyneuropathy (FAP): a single-center experience over 16 years. Am J Transplant. 2007;7:2597-604.

110. Lemos C, Coelho T, Alves-Ferreira M, Martins-da-Silva A, Sequeiros J, Mendonça D, Sousa A. Overcoming artefact: anticipation in 284 Portuguese kindreds with familial amyloid polyneuropathy (FAP) ATTRV30M. J Neurol Neurosurg Psychiatry. 2014;85:326-30.

111. Tashima K, Ando Y, Tanaka Y, Uchino M, Ando M. Change in the age of onset in patients with familial amyloidotic polyneuropathy type I. Intern Med. 1995;34:748-50.

112. Tsuchiya A, Yazaki M, Kametani F, Takei Y, Ikeda S. Marked regression of abdominal fat amyloid in patients with familial amyloid polyneuropathy during long-term follow-up after liver transplantation. Liver Transpl. 2008; 14:563-70.

113. Sekijima Y. Transthyretin (ATTR) amyloidosis: clinical spectrum, molecular pathogenesis and disease-modifying treatments. J Neurol Neurosurg Psychiatry. 2015;86:1036-43.

114. Shimojima Y, Morita H, Kobayashi S, Takei Y, Ikeda S. Ten-year follow-up of peripheral nerve function in patients with familial amyloid polyneuropathy after liver transplantation. J Neurol. 2008:255:1220-5.

115. Herlenius G, Wilczek HE, Larsson M, Ericzon BG. Ten years of international experience with liver transplantation for familial amyloidotic polyneuropathy: results from the Familial Amyloidotic Polyneuropathy World Transplant Registry. Transplantation. 2004;77:64-71.

116. Yamashita T, Ando Y, Okamoto S, Misumi Y, Hirahara T, Ueda M, Obayashi K, Nakamura $\mathrm{M}$, Jono $\mathrm{H}$, Shono $\mathrm{M}$, et al. Long-term survival after liver transplantation in patients with familial amyloid polyneuropathy. Neurology. 2012;78:637-43.

117. Suhr OB, Larsson M, Ericzon BG, Wilczek HE. Survival after transplantation in patients with mutations other than Val30Met: extracts from the FAP World Transplant Registry. Transplantation. 2016;100:373-81.

118. Adams D, Samuel D, Goulon-Goeau C, Nakazato M, Costa PM, Feray C, et al. The course and prognostic factors of familial amyloid polyneuropathy after liver transplantation. Brain. 2000;123:1495-504.

119. Algalarrondo V, Antonini T, Théaudin M, Ducot B, Lozeron P, Chemla D, et al. Prediction of long-term survival after liver transplantation for familial transthyretin amyloidosis. J Am Coll Cardiol. 2015;66:2154-6.

120. Oshima T, Kawahara S, Ueda M, Kawakami Y, Tanaka R, Okazaki T, Misumi Y, Obayashi K, Yamashita T, Ohya Y, et al. Changes in pathological and biochemical findings of systemic tissue sites in familial amyloid polyneuropathy more than 10 years after liver transplantation. J Neurol Neurosurg Psychiatry. 2014;85:740-6.

121. Ihse $E$, Suhr $O B$, Hellman U, Westermark P. Variation in amount of wild-type transthyretin in different fibril and tissue types in ATTR amyloidosis. J Mol Med (Berl). 2011:89:171-80.

122. Liepnieks JJ, Benson MD. Progression of cardiac amyloid deposition in hereditary transthyretin amyloidosis patients after liver transplantation. Amyloid. 2007;14:277-82.

123. Yazaki M, Mitsuhashi S, Tokuda T, Kametani F, Takei YI, Koyama J, Kawamorita A, Kanno H, Ikeda SI. Progressive wild-type transthyretin deposition after liver transplantation preferentially occurs onto myocardium in FAP patients. Am J Transplant. 2007;7:235-42.

124. Sakashita N, Ando Y, Haraoka K, Terazaki H, Yamashita T, Nakamura M, Takeya M. Severe congestive heart failure with cardiac liver cirrhosis 10 years after orthotopic liver transplantation for familial amyloidotic polyneuropathy. Pathol Int. 2006;56:408-12.

125. Hara R, Kawaji T, Ando E, Ohya Y, Ando Y, Tanihara H. Impact of liver transplantation on transthyretin-related ocular amyloidosis in Japanese patients. Arch Ophthalmol. 2010;128:206-10. 
126. Sandgren O, Kjellgren D, Suhr OB. Ocular manifestations in liver transplant recipients with familial amyloid polyneuropathy. Acta Ophthalmol. 2008;86:520-4.

127. Ando $E$, Ando Y, Haraoka K. Ocular amyloid involvement after liver transplantation for polyneuropathy. Ann Intern Med. 2001;135:931-2.

128. Ando $Y$, Terazaki H, Nakamura M, Ando E, Haraoka $K$, Yamashita T, Ueda M, Okabe $H$, Sasaki $Y$, Tanihara $H$, et al. A different amyloid formation mechanism: de novo oculoleptomeningeal amyloid deposits after liver transplantation. Transplantation. 2004;77:345-9.

129. Haraoka K, Ando Y, Ando E, Sun X, Nakamura M, Terazaki H, Misumi S, Tanoue $Y$, Tajiri $T$, Shoji $S$, et al. Presence of variant transthyretin in aqueous humor of a patient with familial amyloidotic polyneuropathy after liver transplantation. Amyloid. 2002;9:247-51.

130. Sekijima Y. Recent progress in the understanding and treatment of transthyretin amyloidosis. J Clin Pharm Ther. 2014;39:225-33.

131. Misumi Y, Narita Y, Oshima T, Ueda M, Yamashita T, Tasaki M, Obayashi K, Isono K, Inomata $Y$, Ando Y. Recipient aging accelerates acquired transthyretin amyloidosis after domino liver transplantation. Liver Transpl. 2016;22:656-64.

132. Sekijima Y. Newly developed drug therapies for familial amyloid polyneuropathy: diflunisal and tafamidis. Brain Nerve. 2014;66:773-781. [Article in Japanese].

133. Said G, Grippon S, Kirkpatrick P. Tafamidis. Nat Rev Drug Discov. 2012;11:185-6

134. Bulawa CE, Connelly S, Devit M, Wang L, Weigel C, Fleming JA, Packman J, Powers ET, Wiseman RL, Foss TR, et al. Tafamidis, a potent and selective transthyretin kinetic stabilizer that inhibits the amyloid cascade. Proc Natl Acad Sci U S A. 2012;109:9629-34.

135. Johnson SM, Connelly S, Fearns C, Powers ET, Kelly JW. The transthyretin amyloidoses: from delineating the molecular mechanism of aggregation linked to pathology to a regulatory-agency-approved drug. J Mol Biol. 2012;421:185-203.

136. Coelho T, Maia LF, da Silva AM, Cruz MW, Planté-Bordeneuve V, Suhr OB, Conceição I, Schmidt HH, Trigo P, Kelly JW, et al. Long-term effects of tafamidis for the treatment of transthyretin familial amyloid polyneuropathy. J Neurol. 2013;260:2802-14.

137. Waddington Cruz M, Amass L, Keohane D, Schwartz J, Li H, Gundapaneni B. Early intervention with tafamidis provides long-term (5.5-year) delay of neurologic progression in transthyretin hereditary amyloid polyneuropathy. Amyloid. 2016;23:178-83.

138. Ando Y, Sekijima Y, Obayashi K, Yamashita T, Ueda M, Misumi Y, Morita H, Machii K, Ohta M, Takata A, et al. Effects of tafamidis treatment on transthyretin (TTR) stabilization, efficacy, and safety in Japanese patients with familial amyloid polyneuropathy (TTR-FAP) with Val30Met and nonVal30Met: a phase III, open-label study. J Neurol Sci. 2016;362:266-71.

139. Sekijima Y, Dendle MA, Kelly JW. Orally administered diflunisal stabilizes transthyretin against dissociation required for amyloidogenesis. Amyloid. 2006;13:236-49.

140. Tojo K, Sekijima Y, Kelly JW, Ikeda S. Diflunisal stabilizes familial amyloid polyneuropathy-associated transthyretin variant tetramers in serum against dissociation required for amyloidogenesis. Neurosci Res. 2006;56:441-9.

141. Berk JL, Suhr OB, Obici L, Sekijima Y, Zeldenrust SR, Yamashita T, Heneghan MA, Gorevic PD, Litchy WJ, Wiesman JF, et al. Repurposing diflunisal for familial amyloid polyneuropathy: a randomized clinical trial. JAMA. 2013;310:2658-67.

142. Whelan CJ, Sattianayagam P, Dungu J, Pinney J, Gibbs S, Banypersad S, Venner C, Lachmann HJ, Wechalekar AD, Gillmore JD, et al. Tolerability of diflunisal therapy in patients with transthyretin amyloidosis. In XIIIth International Symposium on Amyloidosis. May 2012; Abstract OP 56. http:// www.amyloid.nl/Files/Abstract_Book_ISA_2012.pdf. Accessed 21 Apr 2017.

143. Harirforoosh S, Asghar W, Jamali F. Adverse effects of nonsteroidal antiinflammatory drugs: an update of gastrointestinal, cardiovascular and renal complications. J Pharm Pharm Sci. 2013;16:821-47.

144. Sekijima Y, Tojo K, Morita H, Koyama J, Ikeda S. Safety and efficacy of longterm diflunisal administration in hereditary transthyretin (ATTR) amyloidosis. Amyloid. 2015;22:79-83.

145. Ando Y, Yonehara T, Tanaka Y, Tashima K, Uchino M, Ando M. Early pacemaker implantation in patients with familial amyloidotic polyneuropathy. Muscle Nerve. 1996;19:1640-1.

146. Algalarrondo V, Dinanian S, Juin C, Chemla D, Bennani SL, Sebag C, Planté V, Le Guludec D, Samuel D, Adams D, et al. Prophylactic pacemaker implantation in familial amyloid polyneuropathy. Heart Rhythm. 2012;9:1069-75.
147. Dharmarajan K, Maurer MS. Transthyretin cardiac amyloidoses in older north Americans. J Am Geriatr Soc. 2012;60:765-74.

148. Hellman U, Alarcon F, Lundgren HE, Suhr OB, Bonaiti-Pellié C, PlantéBordeneuve $\mathrm{V}$. Heterogeneity of penetrance in familial amyloid polyneuropathy, ATTR Val30Met, in the Swedish population. Amyloid. 2008;15:181-6.

149. Planté-Bordeneuve V, Said G. Familial amyloid polyneuropathy. Lancet Neurol. 2011;10:1086-97.

150. The Familial Amyloidotic Polyneuropathy World Transplant Registry. http:// www.fapwtr.org/ram1.htm. Accessed 26 April 2017.

151. Ackermann EJ, Guo S, Booten S, Alvarado L, Benson M, Hughes S, Monia BP. Clinical development of an antisense therapy for the treatment of transthyretin-associated polyneuropathy. Amyloid. 2012;19(Suppl 1):43-4.

152. Benson MD, Kluve-Beckerman B, Zeldenrust SR, Siesky AM, Bodenmiller DM, Showalter AD, Sloop KW. Targeted suppression of an amyloidogenic transthyretin with antisense oligonucleotides. Muscle Nerve. 2006;33:609-18.

153. Adams D, Coehlo T, Suhr O, Conceição I, Waddington-Cruz M, Schmidt H, Campistol J, Pouget J, Buades J, Berk J, et al. Interim results for phase II trial of ALN-TTR02, a novel RNAi therapeutic for the treatment of familial amyloidotic polyneuropathy. In Biennial Meeting of the Peripheral Nerve Society, St Malo, France. 29 Jun-03 Jul 2013. www.alnylam.com/capella/ presentations/aln-ttr02phiidata/. Accesses 21 Apr 2017.

154. Zimmermann T, Karsten V, Harrop J, Chan A, Chiesa J, Peters G, Falzone R, Cehelsky J, Nochur S, Vaishnaw A, et al. Phase I first-in-humans trial of ALNTTRsc, a novel RNA interference therapeutic for the treatment of familial amyloidotic cardiomyopathy (FAC). J Card Fail 2013:19:S66-S66.

155. Cardoso I, Martins D, Ribeiro T, Merlini G, Saraiva MJ. Synergy of combined doxycycline/TUDCA treatment in lowering transthyretin deposition and associated biomarkers: studies in FAP mouse models. J Transl Med. 2010;8:74.

156. Hosoi A, Su Y, Torikai M, Jono H, Ishikawa D, Soejima K, Higuchi H, Guo J, Ueda M, Suenaga G, et al. Novel antibody for the treatment of transthyretin amyloidosis. J Biol Chem. 2016:291:25096-105.

157. Ikeda S, Nakazato M, Ando Y, Sobue G. Familial transthyretin-type amyloid polyneuropathy in Japan: clinical and genetic heterogeneity. Neurology. 2002;58:1001-7

\section{Submit your next manuscript to BioMed Central and we will help you at every step:}

- We accept pre-submission inquiries

- Our selector tool helps you to find the most relevant journal

- We provide round the clock customer support

- Convenient online submission

- Thorough peer review

- Inclusion in PubMed and all major indexing services

- Maximum visibility for your research

Submit your manuscript at www.biomedcentral.com/submit

) Biomed Central 